Article

\title{
Biomarkers, Master Regulators and Genomic Fabric Remodeling in a Case of Papillary Thyroid Carcinoma
}

\author{
Dumitru A. Iacobas (1) \\ Personalized Genomics Laboratory, CRI Center for Computational Systems Biology, Roy G Perry College of \\ Engineering, Prairie View A\&M University, Prairie View, TX 77446, USA; daiacobas@pvamu.edu; \\ Tel.: +1-936-261-9926
}

Received: 1 August 2020; Accepted: 1 September 2020; Published: 2 September 2020

\begin{abstract}
Publicly available (own) transcriptomic data have been analyzed to quantify the alteration in functional pathways in thyroid cancer, establish the gene hierarchy, identify potential gene targets and predict the effects of their manipulation. The expression data have been generated by profiling one case of papillary thyroid carcinoma (PTC) and genetically manipulated BCPAP (papillary) and 8505C (anaplastic) human thyroid cancer cell lines. The study used the genomic fabric paradigm that considers the transcriptome as a multi-dimensional mathematical object based on the three independent characteristics that can be derived for each gene from the expression data. We found remarkable remodeling of the thyroid hormone synthesis, cell cycle, oxidative phosphorylation and apoptosis pathways. Serine peptidase inhibitor, Kunitz type, 2 (SPINT2) was identified as the Gene Master Regulator of the investigated PTC. The substantial increase in the expression synergism of SPINT2 with apoptosis genes in the cancer nodule with respect to the surrounding normal tissue (NOR) suggests that SPINT2 experimental overexpression may force the PTC cells into apoptosis with a negligible effect on the NOR cells. The predictive value of the expression coordination for the expression regulation was validated with data from $8505 \mathrm{C}$ and BCPAP cell lines before and after lentiviral transfection with $D D X 19 B$.
\end{abstract}

Keywords: 8505C cell line; apoptosis; BCPAP cell line; BRAF; CFLAR; IL6; oxidative phosphorylation; SPINT2; thyroid hormone synthesis; weighted pathway regulation

\section{Introduction}

Thyroid cancer (TC) has a lower incidence and mortality rate compared to other malignancies. Still, in 2020 in the USA, 52,440 new cases (12,270 men and 40,170 women) are expected to be added. Although TC affects over three times more women than men, the number of deaths (2180) is practically equally distributed between the two sexes (1040 men and 1140 women) [1]. There are four major types of thyroid cancers: papillary (hereafter denoted as PTC, $70-80 \%$ of total cases), follicular (FTC, 10-15\%), medullary (MTC, $2 \%$ ) and anaplastic (APC, $~ 2 \%$ ). PTC, FTC and MTC are composed of well-differentiated cells and are treatable, while APC is undifferentiated and has a poor prognosis [2].

Considerable effort has been invested in recent decades to identify DNA mutations and the oncogenes (which turn on) and tumor suppressor factors (which turn off) that are responsible for triggering TC. The 25.0 release (22 July 2020) of the Genomic Data Commons Data Portal [3] includes 11,128 confirmed mutations detected on 13,564 genes sequenced from 1440 (553 male and 887 female) TC cases. The most frequently mutated gene reported in the portal is BRAF (B-Raf proto-oncogene, serine/threonine kinase), with up to 10 mutations identified in $20.56 \%$ of cases. Further down in terms of mutation frequency are: NRAS (neuroblastoma RAS viral (v-ras) oncogene homolog) with two mutations in $2.71 \%$ of cases, TTN (titin), with a total of 40 mutations in $2.29 \%$ of cases, and TG (thyroglobulin), with a total of 26 mutations in $1.67 \%$ of cases [3]. For most genes, the portal [3] shows 
the specific types and locations of the mutations and the cancer form(s) where these mutations were found. However, there is no bi-univocal correspondence between cancer forms and mutated genes: each cancer was associated with numerous mutated genes and mutations of the same gene were identified in several forms of cancer. How many mutated genes does one need in order to decide upon the right form of cancer? Are there exclusive combinations of mutations for a particular form of cancer and only for that form? If present, the number of the affected genes should be large enough to avoid any overlap with other form of cancer. Although the incidence of each particular mutation in the explored cohort of patients is known, it is impossible to determine the predictive values of combinations of mutated genes because for more than three genes the number of possibilities $\left(\geq 2.3 \times 10^{11}\right)$ exceeds the human population of the Earth. Even though one can determine via conditioned probabilities (actual conditioned frequencies) the chance of finding the same combination of mutations in other persons, the diagnostic value is very poor. Moreover, one should not forget that the mutations were identified with respect to a reference human genome obtained by averaging the DNA sequence results from a large number of healthy individuals regardless of race, sex, age, environmental conditions, etc. However, even among genomes of healthy individuals there are $0.1 \%$ (i.e., 3mln nucleotides) differences $(0.6 \%$ when considering indels) [4].

There are several commercially available gene assays used for the preoperative diagnostic and classification of TCs (e.g., [5,6]). Recently, Foundation Medicine [7] compiled a list of 310 genes with full coding exonic regions for the detection of substitutions, insertion-deletions and copy-number alterations. An additional list of the same Foundation contains 36 genes with intronic regions useful for the detection of gene rearrangements (one gene with a promoter region and one non-coding RNA gene) [7]. For all these assays, the question is how many and what genes should be mutated/regulated to assign an accurate diagnostic? Most importantly, how did the researchers determine the predictive values of each combination of genes? In [7], there are 346 combinations of one gene, 59,685 of two, $6,843,880$ combinations of three, 587 million of four and over 40 billion of five and more. Therefore, for practical reasons, only the most relevant three biomarkers, at most, are currently used, which considerably limits the diagnostic accuracy.

While the diagnostic value of mutations and/or regulations is doubtful, what about their use for therapeutic purposes? Is restoring the normal sequence/expression level of one biomarker enough to cure the cancer? Considering that the "trusted" biomarkers were selected from the genes with the most frequently altered sequence and/or expression level in large populations, this means that they are less protected by the cellular homeostatic mechanisms. The cells are supposed to invest energy to protect the sequence and expression level of genes, critical for their survival, proliferation, and integration in multicellular structures. The low level of protection indicates that biomarkers are minor players, and therefore the restoration of their structure/expression level may be of little consequence to the cancer cells.

While we do not see a genomic solution for the cancer diagnostic at present, we believe that our Gene Master Regulator (GMR) approach [8,9] is a reasonable alternative to the actual biomarker-oriented gene therapy. The GMR of a particular cell phenotype is the gene whose highly protected sequence/expression by the cellular homeostatic mechanisms regulates major functional pathways through expression coordination with many of their genes. In our cancer genomic studies [8-10], we found that the GMR of the cancer nodule is very low in the gene hierarchy of the surrounding cancer-free tissue of the tumor. For this reason, manipulation of the GMR's expression is expected to selectively destroy cancer cells without affecting the normal ones much.

In this report, we analyze previously published transcriptomic data [8] to quantify the cancer-related remodeling of major functional pathways in the PTC nodule with respect to the normal tissue of the resection margins (NOR) of a surgically removed thyroid tumor. The Gene Commanding Height (GCH) hierarchy and the GMRs are determined in both PTC and NOR, and the potential regulations of the apoptosis genes in response to the cancer GMR expression manipulation are predicted. The GCH scores of the top genes are compared to those of the most mutated genes in TC 
as well as those of the usually considered cancer biomarkers. Transcriptomic profiles of two standard TC cell lines before and after stable transfection with a gene were used to determine the predictive value of the expression coordination with that gene in untreated cells for the regulation in treated ones. The analysis presented here was derived from the Genomic Fabric Paradigm (GFP) that assigns three independent measures to each gene and considers the transcriptome as a multi-dimensional mathematical object [11].

\section{Materials and Methods}

\subsection{Gene Expression Data}

We used gene expression data from one case of papillary thyroid carcinoma, pathological stage pT3NOMx, deposited in the Gene Expression Omnibus (GEO) of the National Center for Biotechnology Information (NCBI) [12] as GSE97001. In that study, the quarters of the most homogeneous 20-mm ${ }^{3}$ part of the frozen unilateral, single, 32.0-mm PTC nodule and four small pieces from the NOR of the same gland from the same patient were profiled separately. Thus, we got data from four biological replicas of each region. Since each human is subjected to a unique set of transcriptome-regulating factors (race, sex, age, medical history, environmental conditions, exposure to stress and toxins, etc.), the normal tissue surrounding the cancer nodule is a far better reference than tissues from other healthy persons. Expression values were normalized iteratively to the median of all quantifiable genes in all samples and transcript abundances were presented as multiples of the expression level of the median gene in each region.

Transcriptomic data from the surgically removed tumor were compared to the gene expression profiles of two standard human thyroid cancer cell lines: BCPAP (papillary) and 8505C (anaplastic) deposited as GSE97002. We determined the predictive value of the coordination analysis in untreated cells for the expression regulation in treated ones by comparing the transcriptomic profiles of these cell lines before and after stable transfection with DDX19B, NEMP1, PANK2 and UBALD1. The results of transfection with DEAD (Asp-Glu-Ala-Asp) box polypeptide 19B (DDX17B) were collected from GSE97028, those for nuclear envelope integral membrane protein 1 (NEMP1) from GSE97031, for pantothenate kinase 2 (PANK2) from GSE97030 and for UBA-like domain containing 1 (UBALD1) from GSE97427. Although alterations of DDX19B [13], NEMP1 [14] and PANK2 [15] were linked to some forms of cancer by other authors, these genes were selected only because their different GCH scores in the two cell lines made them suitable to validate the GMR approach [8,9].

\subsection{Single-Gene Transcriptomic Quantifiers}

\subsubsection{Biological Replicas, Profiling Redundancy and Average Expression Level}

The four biological replicas experimental design provided for every single gene in each region three independent measures: (i) average expression level, (ii) expression variation and (iii) expression coordination with each other gene [16]. We used these three measures and combinations of them to establish the gene hierarchies and characterize the contribution of each gene to the cancer-related reorganization of the thyroid transcriptome.

The Agilent two-color expression microarrays used in the analyzed experiment redundantly probed the genes with various number of spots from 1 to 20 (as for MIEF1 = mitochondrial elongation factor 1) and SRRT = serrate, RNA effector molecule). Therefore, for each gene " $i$ ", we computed the average expression level over the group of $R_{i}$ spots redundantly probing the same transcript of the average expression levels measured by spot " $k$ " across the biological replicas.

$$
\begin{aligned}
& \mu_{i}^{(\mathrm{NOR} / \mathrm{PTC})}=\frac{1}{R_{i}} \sum_{k=1}^{R_{i}} \mu_{i, k}^{(\mathrm{NOR} / \mathrm{PTC})}=\frac{1}{R_{i}} \sum_{k=1}^{R_{i}}\left(\frac{1}{4} \sum_{j=1}^{4} a_{i, k, j}^{(\mathrm{NOR} / \mathrm{PTC})}\right), \quad \text { where }: \\
& a_{i, k, j}^{(\mathrm{NOR} / \mathrm{PTC})}=\text { expression level of gene " } i \text { " probed by spot " } k \text { " on biological replica " } j \text { " }
\end{aligned}
$$




\subsubsection{Expression Variation}

Because of the probing redundancy, instead of the coefficient of variation $(\mathrm{CV})$, we used the Relative Expression Variability (REV). REV is the Bonferroni-like corrected mid-interval of the chi-square estimate of the pooled CV for all quantifiable transcripts of the same gene [17]

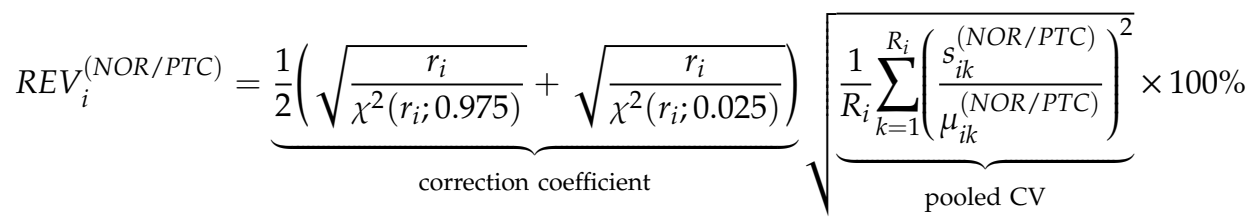

$\mu_{i k}=$ average expression level of gene i probed by spot $\mathrm{k}\left(=1, \ldots, R_{i}\right)$ in the 4 biological replicas

$s_{i k}=$ standard deviation of the expression level of gene i probed by spot $\mathrm{k}$

$r_{i}=4 R_{i}-1=$ number of degrees of freedom

$R_{i}=$ number of microarray spots probing redundantly gene $i$

A lower REV indicates stronger control by the cellular homeostatic mechanisms to limit the expression fluctuations, expected for genes critical for survival, proliferation and phenotypic expression. Therefore, we also use the Relative Expression Control (REC)

$$
\begin{aligned}
& R E C_{i}^{(N O R, P T C)} \equiv \frac{\langle R E V\rangle^{(N O R / P T C)}}{R E V_{i}^{(N O R / P T C)}}-1 \\
& \langle\rangle=\text { median for all genes profiled in that phenotype }
\end{aligned}
$$

As defined, positive $R E C$ s point to genes that are more controlled than the median while negative $R E C$ s identify less controlled genes in that phenotype. It is natural to assume that the cell invests more energy to control the expressions of more important genes for its survival, phenotypic expression and integration into a multi-cellular structure. As such, REC is a major factor to consider in establishing the gene hierarchy.

\subsubsection{Expression Coordination}

The expression coordination of two genes in the same region was quantified by their pair-wise momentum-product Pearson correlation coefficient between the two sets of expression levels across

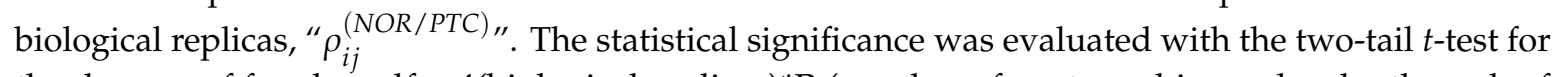
the degrees of freedom $\mathrm{df}=4$ (biological replicas) ${ }^{*} \mathrm{R}$ (number of spots probing redundantly each of the correlated transcripts) -2 . Two genes were considered as synergistically expressed (positive or in-phase coordination) if their expression levels fluctuated in phase across biological replicas. They are considered as antagonistically expressed (negative or anti-phase coordination) when their expression levels manifest opposite tendencies and are independently expressed (neutral coordination) when the expression fluctuations of one gene are not related to the fluctuations of the other [17]. Although not (yet) validated through molecular biology studies, the expression coordination was speculated to reflect the "transcriptomic stoichiometry" of the encoded proteins that are produced in certain proportions to optimize the cellular functional pathways [18].

We also computed the coordination power $C P_{i, \Gamma}^{(N O R / P T C)}$ [19] and the Overall Coordination $O C_{i, \Gamma}^{(N O R / P T C)}$ of a gene " $i$ " with respect to the functional pathway " $\Gamma$ " in each of the two profiled regions (NOR and PTC)

$$
\left.C P_{i, \Gamma}^{(\mathrm{NOR} / \mathrm{PTC})} \equiv \overline{\rho_{i j}^{(\mathrm{NOR} / \mathrm{PTC})}}\right|_{\forall j \in \Gamma . j \neq i} \times 100 \%, \quad O C_{i, \Gamma}^{(\mathrm{NOR} / \mathrm{PTC})} \equiv \exp \left(\frac{4}{N} \sum_{j \in \Gamma, j \neq i} \rho_{i j}^{2}-1\right)
$$

Both $C P_{i, \Gamma}^{(N O R / P T C)}$ and $O C_{i, \Gamma}^{(N O R / P T C)}$ are measures of the gene " $i$ " influence on " $\Gamma$ ". 


\subsection{Gene Commanding Height (GCH) and Gene Master Regulator (GMR)}

In previous papers [8-10], we introduced the Gene Commanding Height (GCH), a combination of the expression control and expression coordination with all (ALL) other genes, to establish the gene hierarchy in each phenotype

$$
G C H_{i}^{(N O R, P T C)} \equiv\left(R E C_{i}^{(N O R, P T C)}+1\right) O C_{i, A L L}^{(N O R / P T C)} \equiv \frac{\langle R E V\rangle^{(N O R / P T C)}}{R E V_{i}^{(N O R / P T C)}} \exp \left(\frac{4}{N} \sum_{j \in A L L, j \neq i} \rho_{i j}^{2}-1\right)
$$

The top gene (highest GCH) in each phenotype was termed Gene Master Regulator (GMR) of that phenotype. The very strict control of the GMR expression suggests that this gene is utterly important for cell survival, while the very high overall coordination indicates how much its expression regulates the expression of many other genes.

\subsection{Expression Regulation}

A gene was considered as significantly regulated in the PTC with respect to the NOR if the absolute expression ratio exceeds the cut-off (CUT) value computed individually for each gene by considering the expression variabilities of that gene in both compared conditions [9].

$$
\begin{aligned}
& \left|x_{i}^{(N O R \rightarrow P T C)}\right|>C U T_{i}=1+\frac{1}{100} \sqrt{2\left(\left(R E V_{i}^{(N O R)}\right)^{2}+\left(R E V_{i}^{(P T C)}\right)^{2}\right)} \text {, where : } \\
& x_{i} \equiv\left\{\begin{array}{cc}
\frac{\mu_{i}^{(P T C)}}{\mu_{i}^{(N O R)}}, & \text { if } \mu_{i}^{(P T C)}>\mu_{i}^{(N O R)} \\
-\frac{\mu_{i}^{(N O R)}}{\mu_{i}^{(P T C)}}, & \text { if } \mu_{i}^{(P T C)}<\mu_{i}^{(N O R)}, \mu_{i}^{(P T C / N O R)}=\frac{1}{R_{i}} \sum_{k=1}^{R_{i}} \mu_{i k}^{(P T C / N O R)}
\end{array}\right.
\end{aligned}
$$

The "CUT" criterion for individual genes eliminates the false positives and the false negatives selected by considering uniform absolute fold-change cut-off (e.g., 1.5x). In addition to the percentage of up- and down-regulated genes (that considers all genes as equal contributors to the alteration of a pathway), or the expression ratios " $x$ ", we prefer the Weighted Individual (gene) Regulation [20], "WIR":

$$
\begin{aligned}
& \text { WIR } R_{i}^{(N O R \rightarrow P T C)} \equiv \mu_{i}^{(N O R)} \frac{x_{i}}{\left|x_{i}\right|}\left(\left|x_{i}\right|-1\right)\left(1-p_{i}\right) \text { where }: \\
& \mu_{i}^{(N O R)}=\text { average expression in the normal tissue, } \\
& p_{i}=\mathrm{p} \text {-value of the regulation }
\end{aligned}
$$

Note that in Equation (7), WIR takes into account the normal expression of that gene (i.e., in NOR), its expression ratio (PTC vs. NOR) and the confidence interval (1-p) of the regulation.

\subsection{Quantifiers of the Functional Genomic Fabrics}

The Kyoto Encyclopedia of Genes and Genomes [21,22] was used to select the genes involved in the thyroid hormone synthesis (THS), cell cycle (CC) and oxidative phosphorylation (OPH), as well as how experimental manipulation of the PTC GMR might regulate the programmed cell death (apoptosis, APO). Although almost all functional pathways were perturbed in cancer, THS, CC, OPH and APO were selected because of their importance for the thyroid function and cancer development. There are reports of altered THS in cancer progression and apoptosis (e.g., [23]) and the role of the thyroid hormone in regulating the cell-cycle [24] and the oxidative phosphorylation [25].

Median REC over a gene selection (e.g., apoptosis pathway) was used to compare the expression controls of that selection in different regions or two different gene selections in the same region. Alteration of the genomic fabrics was quantified by the average " $X$ " of the absolute expression ratios 
and by Weighted Pathway Regulation (WPR), the average of the absolute WIRs over a particular "selection" of genes

$$
\begin{aligned}
& X_{\text {selection }}^{(\mathrm{NOR} \rightarrow P T C)} \equiv \overline{\left.x_{i}^{(N O R \rightarrow P T C)}\right|_{\forall i \in \text { selection }}} \\
& W P R_{\text {selection }}^{(N O R \rightarrow P T C)} \equiv \overline{\left|W I R_{i}^{(N O R \rightarrow P T C)}\right|_{\forall i \in \text { selection }}}
\end{aligned}
$$

\section{Results}

\subsection{Overall Results}

A total of 14,903 well-quantified unigenes in all PTC and NOR samples, and in BCPAP and 8505C cells before and after transfection with one of the four targeted genes, were considered in the sequent analyses. The groups redundantly probing the same transcript were replaced by their averages in each biological replica. Eukaryotic translation elongation factor $1 \propto 1$ (EEF1A1) had the largest expression (82.31 median gene expression units) in NOR (not significantly regulated in PTC). Niemann-Pick disease, type C2 (NPC2) had the largest expression in PTC (86.97 median gene expression units), up-regulated by $7.24 \mathrm{x}$ with respect to NOR. Notch 1 (NOTCH1) with 82.35 had the largest expression in the BCPAP cells and myelin protein zero-like 3 (MPZL3) with 107.60 tops the gene expression level in the $8505 \mathrm{C}$ cells.

Out of the quantified unigenes, 1225 (8.22\%) were down-regulated and 1852 (12.42\%) were up-regulated in PTC with respect to NOR. The average absolute PTC/NOR expression ratio for all genes was $X=1.768$ (median $|x|=1.309$ ) and the WPR was 1.071 (median WIR $=0.046$ ). Chitinase 3-like 1 (CHI3L1) was the most up-regulated $(x=219.38)$ and trefoil factor 3 (intestinal) (TFF3) the most down-regulated (x-99.86) gene in PTC. Because expression coordination and average expression level are independent measures, the high regulation of these genes in PTC with respect to NOR has no relevance for their networking in either of the two profiled regions.

\subsection{Three Independent Measures for Each Gene}

Figure 1 illustrates the independence of the three measures for the first 50 alphabetically ordered genes involved in the KEGG-derived [22] human apoptosis pathway (hsa04210). We chose IL6 (interleukin 6) to illustrate the expression coordination of apoptotic genes owing to the significant role of the encoded protein (IL6) in the PTC development [26]. However, coordination with any other gene supports the same conclusion. In addition to the clear independence of the three measures, transcriptomic differences between the two histo-pathologically distinct profiled regions from the thyroid are evident.

In this gene selection, FBJ murine osteosarcoma viral oncogene homolog (FOS) has the highest average expression level (45.37) in NOR (significantly down-regulated by $-2.06 x$ in PTC). Cathepsin H (CTSH) had the largest expression (35.23), up-regulated by 6.78x with respect to NOR. FOS, cathepsin $\mathrm{K}(C T S K)$ and inhibitor of kappa light polypeptide gene enhancer in B-cells kinase $\gamma(I K B K G)$ were among the significantly down-regulated genes. In contrast, $B I D$ (H3 interacting domain death agonist), CTSH and DIABLO (diablo, IAP-binding mitochondrial protein), were among the up-regulated genes of the selection.

CASP8 and FADD-like apoptosis regulator (CLFAR) was the most variably expressed gene in the normal tissue and DNA fragmentation factor $(D F F B), 40 \mathrm{kDa}, \beta$ polypeptide (caspase-activated DNase) the most variably expressed in PTC. Note that most of the selected genes have larger expression variability in the normal tissue than in the cancer nodule. This result confirms our previous reports (see Discussions) about diseases triggering increased control exerted by the cellular homeostatic mechanisms on the transcripts abundances as a way to protect against extensive damages.

Observe also that $20(40 \%)$ of the illustrated apoptotic genes are synergistically expressed with IL6 in the normal tissue and only two (4\%) in the PTC nodule, suggesting the decoupling of the programmed cell death from the inflammatory response in cancer. 

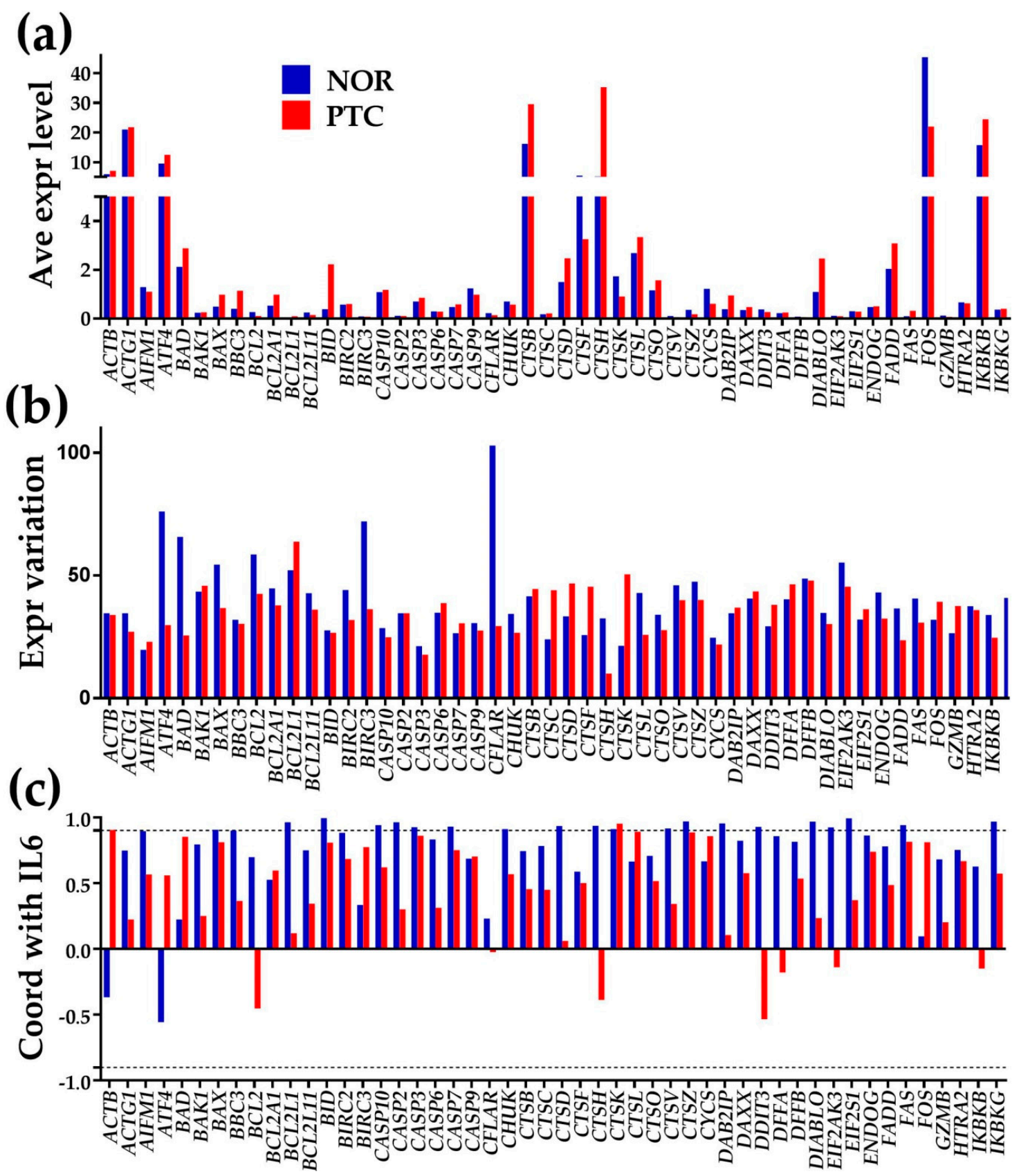

Figure 1. Three independent characteristics of every gene in each region. (a) average expression level, (b) expression variation and (c) expression coordination (here with IL6). The dashed black lines in panel (c) indicate the interval out of which the positive/negative coordination is considered as statistically significant.

\subsection{Expression Regulation}

Figure 2 illustrates the contributions of the first 50 alphabetically ordered quantified oncogenes to the overall regulation in PTC measured by the percentages of the up- and down-regulated genes, expression ratios and weighted individual (gene) regulations. The percentages are restricted to only the significantly regulated genes (considered as equal $-1 /+1$ contributors). By contrast, both $X$ and WIR take into account all (regulated and not regulated) genes and the contributions of these genes are no longer uniform. More informative than the expression ratio, WIR weights the contribution of each gene by its normal expression level (i.e., in NOR), fold-change in cancer and statistical significance of the regulation. 

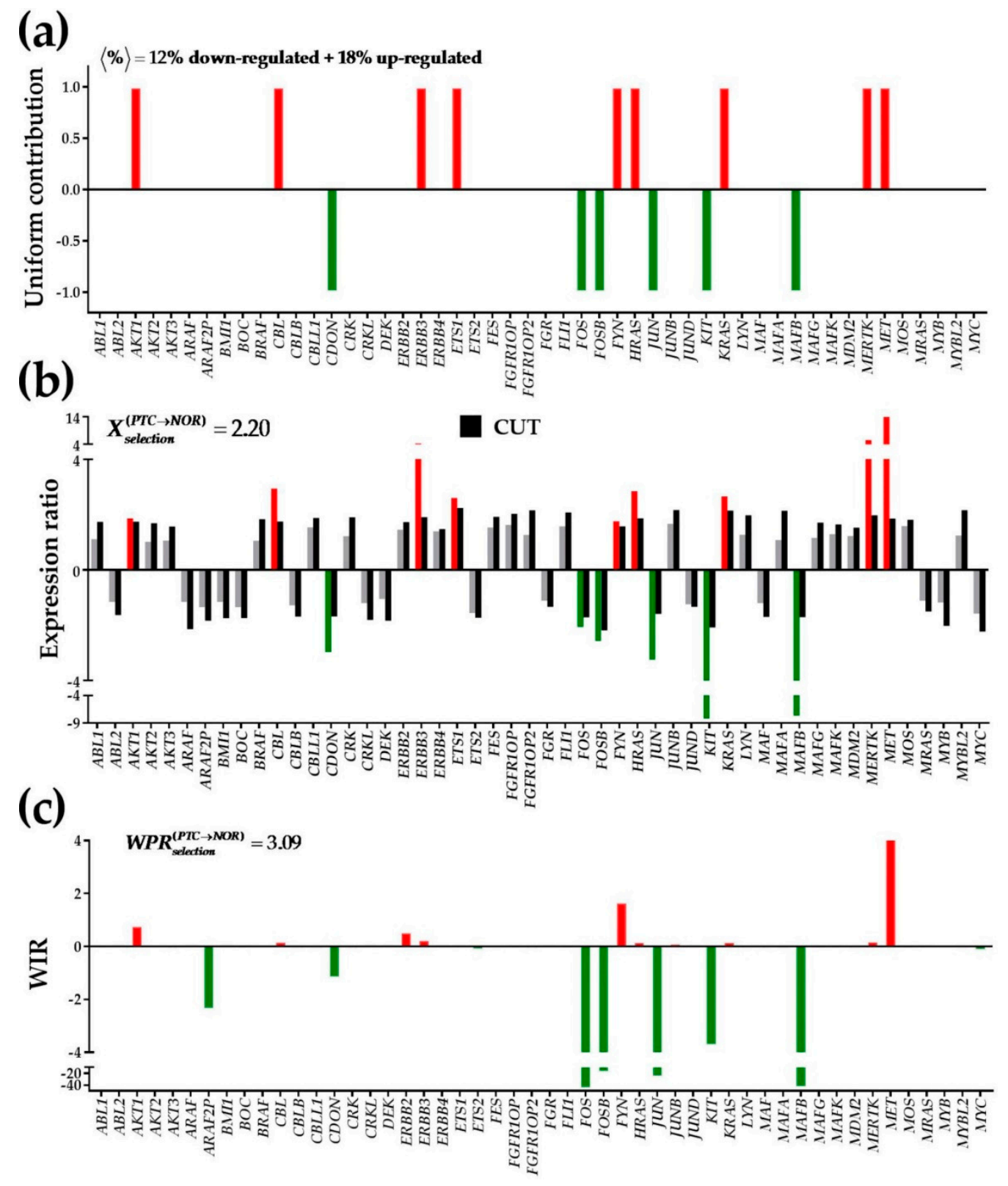

Figure 2. Three ways to consider the contribution of a gene to the pathway regulation. (a) uniform; (b) by expression ratio; (c) as Weighted Individual (gene) Regulation. Red/green/grey columns indicate up-/down-/not regulated genes. Black columns are the fold-change cut-offs (negative for down-regulation). Regulated genes: v-akt murine thymoma viral oncogene homolog 1 (AKT1), $\mathrm{Cbl}$ proto-oncogene, E3 ubiquitin protein ligase $(C B L)$, cell adhesion associated, oncogene regulated $(C D O N)$, v-erb-b2 avian erythroblastic leukemia viral oncogene homolog 3 (ERBB3), v-ets avian erythroblastosis virus E26 oncogene homolog 1 (ETS1), homologs of FBJ murine osteosarcoma viral oncogene (FOS/FOSB), FYN proto-oncogene, Src family tyrosine kinase (FYN), Harvey rat sarcoma viral oncogene homolog (HRAS), jun proto-oncogene (JUN), Kirsten rat sarcoma viral oncogene homolog (KRAS), v-yes-1 Yamaguchi sarcoma viral related oncogene homolog (LYN), v-maf avian musculoaponeurotic fibrosarcoma oncogene homolog B (MAFB), c-mer proto-oncogene tyrosine kinase (MERTK) and met proto-oncogene (MET). 


\subsection{Regulation of the Thyroid Hormone Synthesis}

Figure 3 presents the regulations of the genes involved in the (KEGG-determined) thyroid hormone synthesis (hsa04918). In this pathway, 10.0 (20\%) of the 50 quantified genes were up-regulated and six $(12 \%)$ were down-regulated.

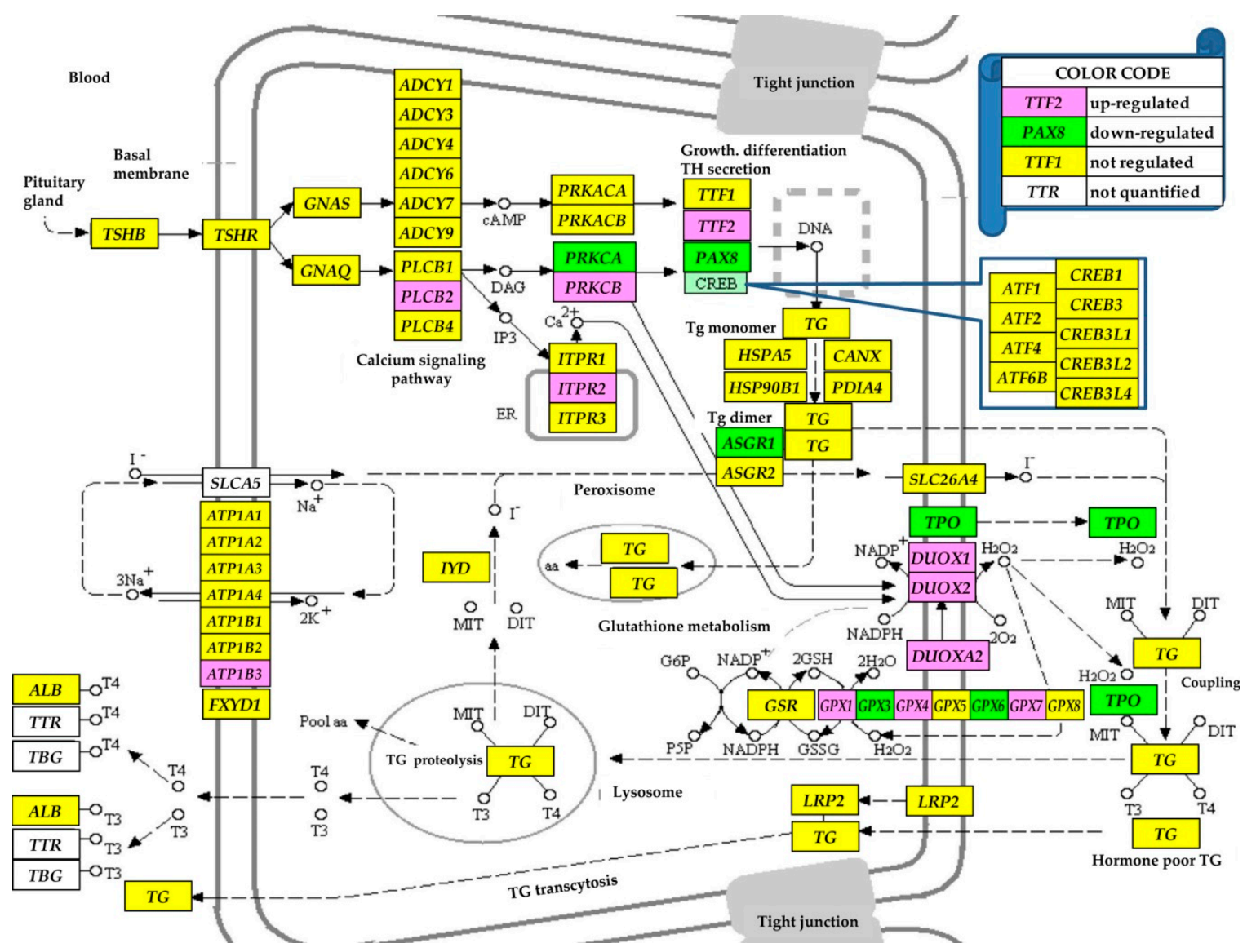

Figure 3. Regulation of thyroid hormone synthesis pathway (modified from hsa04918). Regulated genes: asialoglycoprotein receptor 1 (ASGR1), ATPase, $\mathrm{Na}+\mathrm{K}+$ transporting, $\beta 3$ polypeptide (ATP1B3), dual oxidases (DUOX1/2), dual oxidase maturation factor 2 (DUOXA2), glutathione peroxidases (GPX1/3/4/6/7), inositol 1,4,5-trisphosphate receptor, type 2 (ITPR2), paired box 8 (PAX8), protein kinases $\mathrm{C}(P R K C A / B)$, thyroid peroxidase (TPO) and transcription termination factor, RNA polymerase II (TTF2).

\subsection{Regulation of the Cell-Cycle Pathway}

Figure 4 presents the regulation of the genes involved in the (KEGG-determined) cell cycle pathway (hsa04110), where, out of the 93 genes quantified, three (3.23\%) were down-regulated and 14 (15.05\%) were up-regulated. Except PTTG2, all other regulated genes are located in the DNA replication (S-phase) and the two temporal gaps, G1 and G2, separating the S phase from mitosis (M-phase), indicating faster replication but stationary differentiation. 


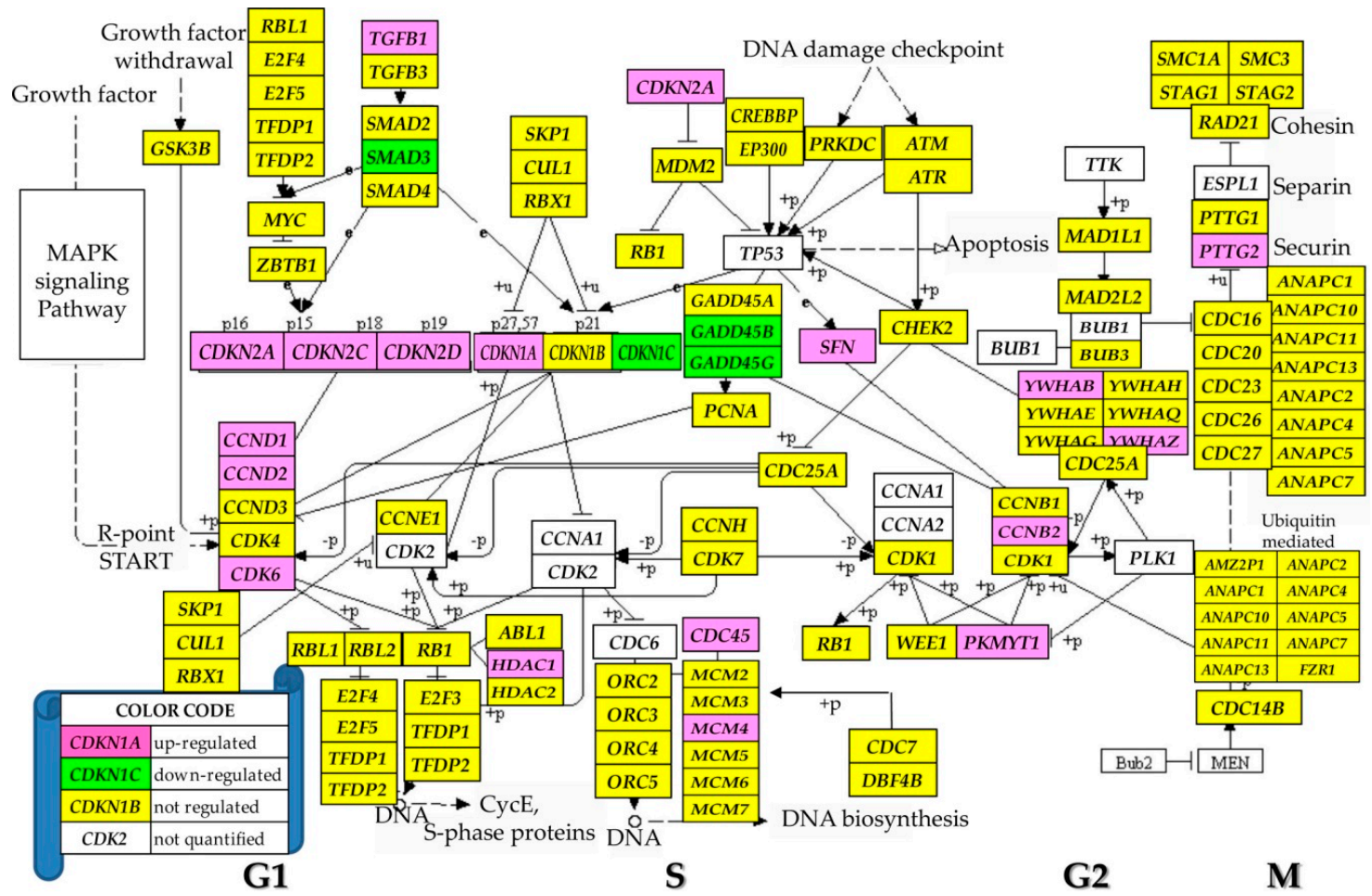

Figure 4. Regulation of the KEGG-determined cell cycle (hsa04110). Regulated genes: cyclins (CCNB2/D1/D2), cell division cycle 45 (CDC45), cyclin-dependent kinase inhibitors $(C D K N 1 A / 1 C / 2 A / 2 C / 2 D)$, growth arrest and DNA-damage-inducibles (GADD45B/D), histone deacetylase 1 (HDAC1), minichromosome maintenance complex component 4 (MCM4), membrane associated tyrosine/threonine 1 (PKMYT1), pituitary tumor-transforming 2 (PTTG2), stratifin $(S F N)$, SMAD family member 3 (SMAD3), transforming growth factor, $\beta 1$ (TGFB1) and tyrosine 3-monooxygenase/tryptophan 5-monooxygenase activation proteins ( $Y W H A B / Z$ ).

\subsection{Remodeling of the Oxidative Phosphorylation Pathway}

Figure 5 presents the remodeling of the coordination networks interlinking the five complexes ([C1], [C2], [C3], [C4], [C5]) of the oxidative phosphorylation in the PTC nodule with respect to NOR tissue. The genes were selected from the KEGG hsa 00190. Note the substantial increase in the synergistically expressed gene pairs in PTC (273) with respect of the NOR (155) and that there is no antagonistically expressed gene pair in PTC, while in NOR there are 105. When the coordination inside each complex is added, there are 781 synergistic and 0 antagonistic pairs in PTC versus 458 synergistic and 242 antagonistic pairs in NOR. In addition to the eight up-regulated and three down-regulated genes within the selection of the 92 oxidative-phosphorylation genes, these results indicate a significant increase in the coordination of the complexes involved in the OP activity. 

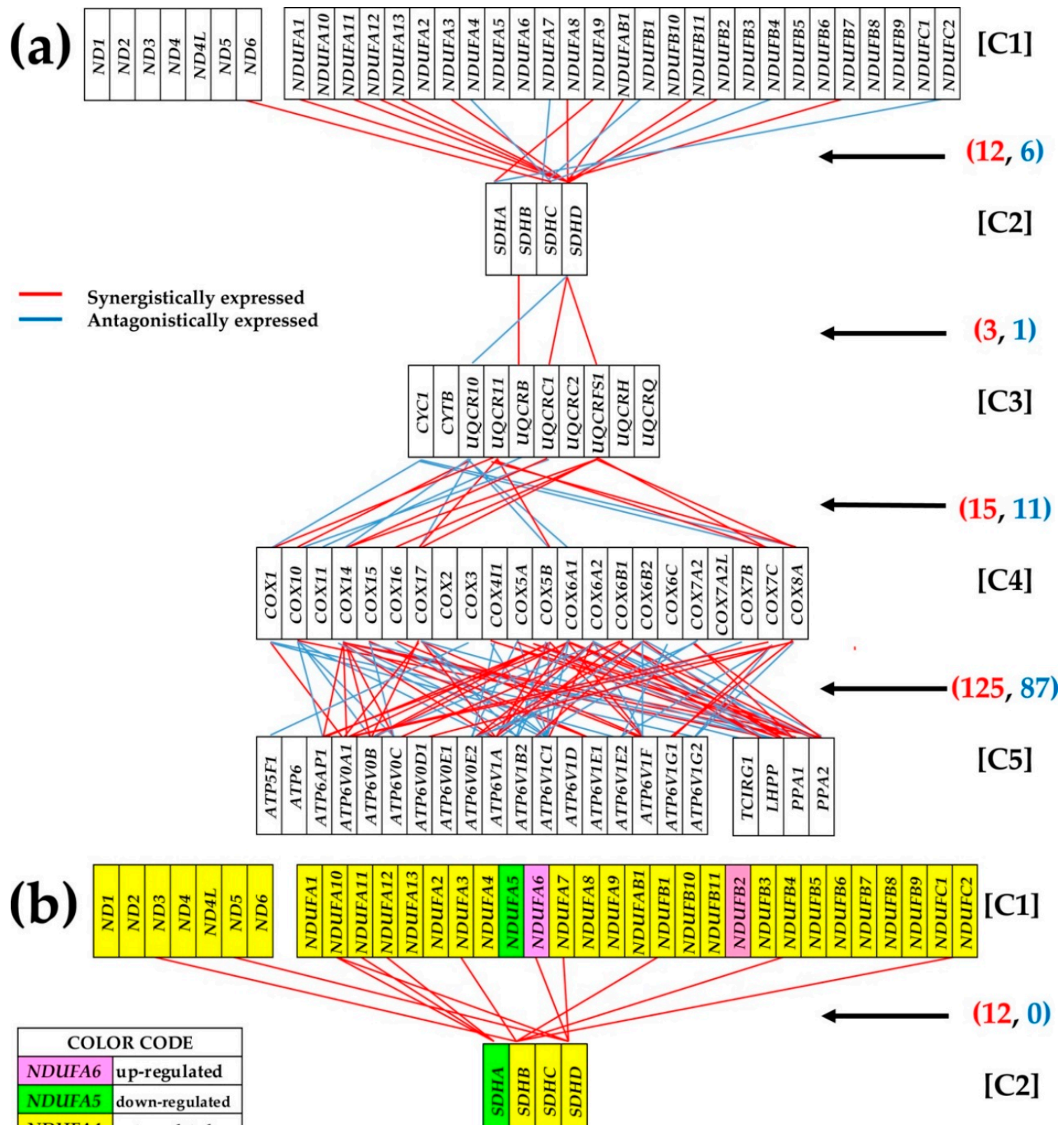

NDUFA4 notregulated

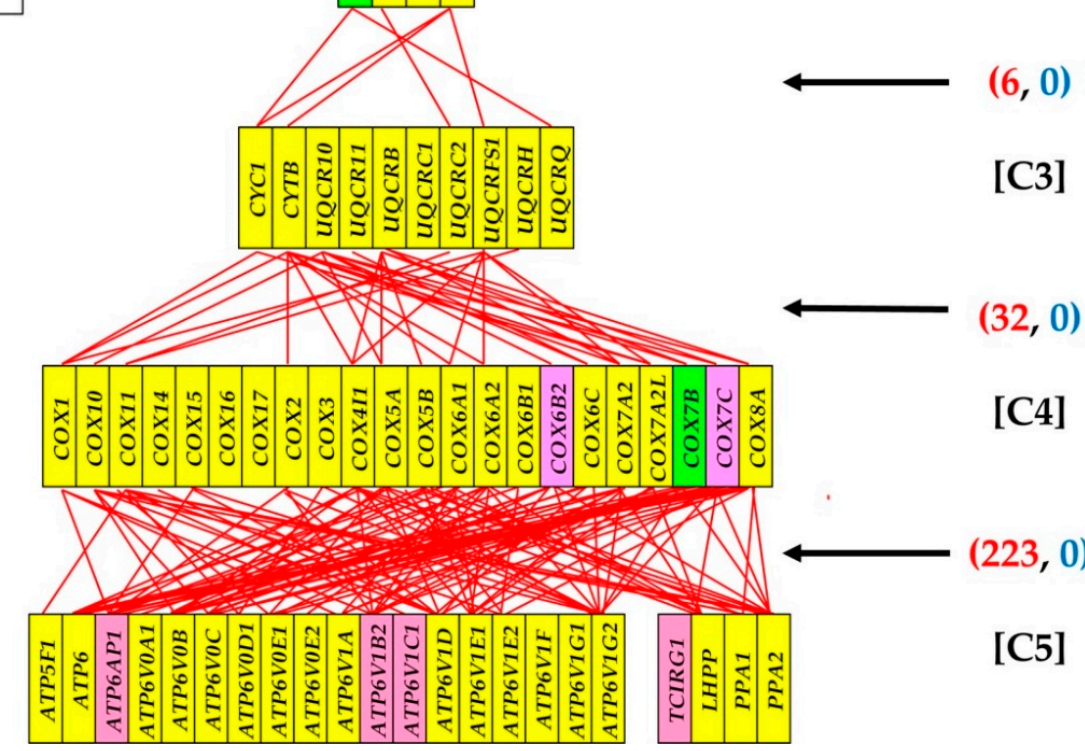

Figure 5. Remodeling of the coordination networks among the five complexes of the oxidative phosphorylation in the PTC nodule with respect to NOR tissue. The red/blue lines indicate that the 
connected genes are synergistically/antagonistically expressed in that region. Red/blue numbers in parentheses indicate the number of synergistically/antagonistically expressed gene pairs between the two complexes. Regulated genes: ATPase, $\mathrm{H}+$ transporting, lysosomal proteins (ATP6AP1, ATP6V1B2, ATP6V1C1), cytochrome c oxidase subunits (COX6B2, COX7B,COX7C), NADH dehydrogenase (ubiquinone) $1 \alpha / \beta$ subcomplexes (NDUFA5, NDUFA6, NDUFB2), succinate dehydrogenase complex, subunit A, flavoprotein $(\mathrm{Fp})(S D H A)$ and T-cell, immune regulator 1, ATPase, $\mathrm{H}+$ transporting, lysosomal V0 subunit A3 (TCIRG1).

\subsection{Gene Hierarchy}

Figure 6 presents the GCH scores of the 12 most frequently mutated genes in TC (reported in [1]) and the top 12 genes in NOR and PTC. Mutated genes: B double prime 1, subunit of RNA polymerase III transcription initiation factor IIIB (BDP1), B-Raf proto-oncogene, serine/threonine kinase (BRAF), $D S T$ (dystonin), eukaryotic translation initiation factor 1A, X-linked (EIF1AX), Harvey rat sarcoma viral oncogene homolog (HRAS), lysine (K)-specific methyltransferase 2A (KMT2A), microtubule-actin crosslinking factor 1 (MACR1), metastasis associated lung adenocarcinoma transcript 1 (non-protein coding) (MALAT1), neuroblastoma RAS viral (v-ras) oncogene homolog (NRAS), thyroglobulin (TG), ubiquitin-specific peptidase 9, X-linked (USP9X), zinc finger homeobox 3 (ZFHX3). Note that none of the most frequently mutated genes are among the top 12 genes in either region. Even $B R A F$, mutated in $20.56 \%$ of the 1440 cases, has no competitive GCH to be a good candidate for the PTC gene therapy (GCH of BRAF in PTC is 11.79). However, SPINT2, the PTC's GMR $\left(G C H_{\text {SPINT2 }}^{(P T C)}=54.97\right)$, appears to be the most legitimate target for this case. While significant alteration of the expression of SPINT2 would have lethal impact on the cancer cells, due to the very low GCH in NOR $\left(G C H_{\text {SPINT2 }}^{(N O R)}=1.93\right)$, it might have very little consequences on the normal cells. Importantly, the GCH scores of the top genes in PTC are substantially lower in NOR and vice-versa.

For comparison, we added the GCH scores of the top 23 genes in each of the standard TC cell lines BCPAP (papillary) and 8505C (anaplastic). Remarkably, 14 genes in the BCPAP cells and three genes in the 8505C cells have GCH scores higher than SPINT2 in PTC. As an additional reference, Figure $\mathrm{S} 1$ shows the GCH scores of most of the genes from FoundationOne ${ }^{\circledR} \mathrm{CDx}$ (Foundation Medicine, Cambridge, MA, U.S.A.) used by Foundation Medicine [7] for genomic testing of solid tumors, including "Non-Small Cell Lung (NSCLC), Colorectal, Breast, Ovarian, and Melanoma. The list contains genes with full coding exonic regions for the detection of substitutions, insertion-deletions (indels), and copy-number alterations (CNAs). It also includes genes with select intronic regions for the detection of gene rearrangements, one gene with a promoter region (telomerase reverse transcriptase (TERT)) and one non-coding RNA gene (TERC). These genes might be useful for diagnostic purposes. However, with their GCH score far below the GMR's and with not enough difference between PTC and NOR, they should have little therapeutic value for this particular case. Substantially lower than the PTC GMR were the biomarkers, oncogenes, apoptosis genes and the ncRNAs determined in the same specimens and presented in Figure 2 from [8]. 

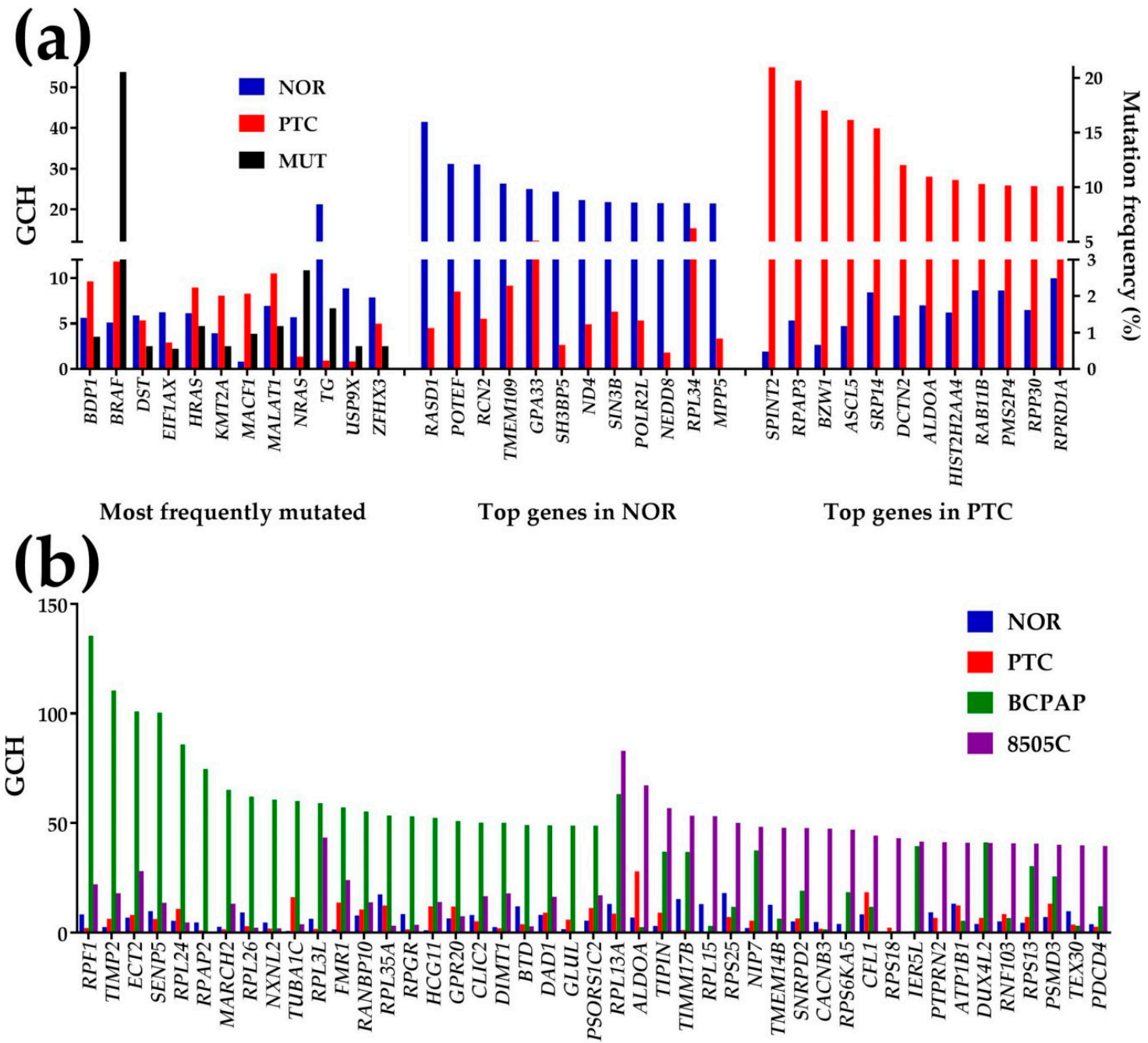

Figure 6. Gene Commanding Height (GCH). (a) GCH and mutation frequency of the 12 reported most frequently mutated genes and the top 12 genes in the normal tissue (NOR) and the papillary nodule (PTC). The mutation frequency is plotted on the right axis. (b) GCH of the top 23 genes in the papillary (BCPAP) and anaplastic (8505C) thyroid cancer cell lines and their scores in NOR and PTC. Top 3 genes in NOR: RAS, dexamethasone-induced 1 (RASD1), POTE ankyrin domain family, member F (POTEF), reticulocalbin 2, EF-hand calcium binding domain (RCN2). Top 3 genes in PTC: serine peptidase inhibitor, Kunitz type, 2 (SPINT2), RNA polymerase II associated protein 3 (RPAP3), basic leucine zipper and W2 domains 1 (BZW1). Top 3 genes in BCPAP cells: ribosome production factor 1 homolog (S. cerevisiae) (RPF1), TIMP metallopeptidase inhibitor 2 (TIMP2), epithelial cell transforming 2 (ECT2). Top 3 genes in 8505C cells: ribosomal protein L13a (RPL13A), aldolase A, fructose-bisphosphate (ALDOA), TIMELESS interacting protein (TIPIN).

\subsection{The Gene Master Regulator at Play}

Our study identified SPINT2, a not regulated gene in the investigated PTA, as the GMR of this patient's malignancy. What are the mechanisms by which experimental alteration of SPINT2 expression might selectively kill the cancer cells but not the normal ones? SPINT2 is highly coordinated with numerous genes from almost all major functional pathways. However, we considered that apoptosis might be the best candidate to evaluate (from a bioinformatics point of view) the effects of SPINT2 manipulation. Therefore, we analyzed the expression coordination of SPINT2 with the 112 apoptosis genes quantified in the two regions. Table 1 presents the apoptosis genes that are significantly up/down regulated in PTC or/and significantly synergistically/antagonistically/independently expressed with SPINT2 in NOR or/and PTC. 
Table 1. Apoptosis genes that are significantly up(U)/down(D) regulated in PTC with respect to NOR or/and significantly synergistically (S)/antagonistically (A)/independently (I) expressed with SPINT2 in NOR or/and PTC.

\begin{tabular}{|c|c|c|c|c|}
\hline GENE & DESCRIPTION & NOR & PTC & REG \\
\hline ACTG1 & actin, $\gamma 1$ & S & & \\
\hline AKT1 & $\mathrm{v}$-akt murine thymoma viral oncogene homolog 1 & & & $\mathrm{U}$ \\
\hline AKT3 & $v$-akt murine thymoma viral oncogene homolog 3 & & $\mathrm{~S}$ & \\
\hline ATF4 & activating transcription factor 4 & A & & \\
\hline ATM & ataxia telangiectasia mutated & & S & \\
\hline$B A K 1$ & BCL2-antagonist/killer 1 & & S & \\
\hline$B A X$ & BCL2-associated $X$ protein & & & $\mathrm{U}$ \\
\hline$B B C 3$ & BCL2 binding component 3 & & $\mathrm{~S}$ & U \\
\hline BCL2 & B-cell CLL/lymphoma 2 & I & & \\
\hline$B C L 2 A 1$ & BCL2-related protein A1 & & & U \\
\hline$B C L 2 L 1$ & BCL2-like 1 & & $\mathrm{~S}$ & \\
\hline BCL2L11 & BCL2-like 11 & & S & \\
\hline BID & $\mathrm{BH} 3$ interacting domain death agonist & & & $\mathrm{U}$ \\
\hline BIRC5 & baculoviral IAP repeat containing 5 & & & $\mathrm{U}$ \\
\hline CAPN1 & calpain $1,(\mathrm{mu} / \mathrm{I})$ large subunit & & $\mathrm{S}$ & \\
\hline CASP2 & caspase 2 , apoptosis-related cysteine peptidase & & S & \\
\hline CASP3 & caspase 3 , apoptosis-related cysteine peptidase & & & U \\
\hline CASP6 & caspase 6 , apoptosis-related cysteine peptidase & & $\mathrm{S}$ & \\
\hline CASP9 & caspase 9 , apoptosis-related cysteine peptidase & $\mathrm{S}$ & & \\
\hline CFLAR & CASP8 and FADD-like apoptosis regulator & & S & \\
\hline CTSC & cathepsin C & & & U \\
\hline CTSD & cathepsin D & & $\mathrm{S}$ & \\
\hline $\mathrm{CTSH}$ & cathepsin $\mathrm{H}$ & & & U \\
\hline CTSK & cathepsin $\mathrm{K}$ & & & $\mathrm{D}$ \\
\hline CTSL & cathepsin L & $\mathrm{S}$ & & \\
\hline CTSV & cathepsin V & & $\mathrm{S}$ & \\
\hline CYCS & cytochrome c, somatic & S & & $\mathrm{D}$ \\
\hline$D A B 2 I P$ & DAB2 interacting protein & & $\mathrm{S}$ & $\mathrm{U}$ \\
\hline DFFA & DNA fragmentation factor & & $\mathrm{S}$ & \\
\hline DIABLO & diablo, IAP-binding mitochondrial protein & & S & U \\
\hline EIF2AK3 & eukaryotic translation initiation factor $2-\alpha$ kinase 3 & & $\mathrm{~S}$ & \\
\hline EIF2S1 & eukaryotic translation initiation factor 2 , subunit $1 \alpha$ & & $\mathrm{S}$ & \\
\hline FAS & Fas cell surface death receptor & & & U \\
\hline FOS & FBJ murine osteosarcoma viral oncogene homolog & & & $\mathrm{D}$ \\
\hline GZMB & $\begin{array}{c}\text { granzyme B (granzyme 2, cytotoxic } \\
\text { T-lymphocyte-associated serine esterase 1) }\end{array}$ & & $\mathrm{S}$ & $\mathrm{D}$ \\
\hline$I K B K B$ & $\begin{array}{l}\text { inhibitor of kappa light polypeptide gene enhancer in } \\
\text { B-cells, kinase } \beta\end{array}$ & I & $S$ & \\
\hline ITPR2 & inositol 1,4,5-trisphosphate receptor, type 2 & & & $\mathrm{U}$ \\
\hline JUN & jun proto-oncogene & & & $\mathrm{D}$ \\
\hline LMNA & $\operatorname{lamin} \mathrm{A} / \mathrm{C}$ & & & $\mathrm{U}$ \\
\hline LMNB2 & lamin B2 & & $\mathrm{S}$ & \\
\hline MAP2K1 & mitogen-activated protein kinase kinase 1 & & & $\mathrm{U}$ \\
\hline MAP2K2 & mitogen-activated protein kinase kinase 2 & & $\mathrm{~S}$ & \\
\hline МАРЗК9 & mitogen-activated protein kinase kinase kinase 9 & & $\mathrm{~S}$ & \\
\hline MAPK1 & mitogen-activated protein kinase 1 & & S & \\
\hline MAPK3 & mitogen-activated protein kinase 3 & & $\mathrm{~S}$ & \\
\hline NFKB1 & $\begin{array}{l}\text { nuclear factor of kappa light polypeptide gene enhancer } \\
\text { in B-cells } 1\end{array}$ & S & & \\
\hline NFKBIA & $\begin{array}{c}\text { nuclear factor of kappa light polypeptide gene enhancer } \\
\text { in B-cells inhibitor, } \alpha\end{array}$ & & & $\mathrm{D}$ \\
\hline NRAS & neuroblastoma RAS viral (v-ras) oncogene homolog & & S & \\
\hline PARP1 & poly (ADP-ribose) polymerase 1 & & & $\mathrm{U}$ \\
\hline PARP4 & poly (ADP-ribose) polymerase family, member 4 & & $\mathrm{~S}$ & \\
\hline PDPK1 & 3-phosphoinositide dependent protein kinase 1 & & S & \\
\hline PIK3CA & $\begin{array}{l}\text { phosphatidylinositol-4,5-bisphosphate 3-kinase, } \\
\text { catalytic subunit } \alpha\end{array}$ & & $\mathrm{S}$ & \\
\hline
\end{tabular}


Table 1. Cont.

\begin{tabular}{|c|c|c|c|c|}
\hline GENE & DESCRIPTION & NOR & PTC & REG \\
\hline PIK3R1 & phosphoinositide-3-kinase, regulatory subunit 1 & & & $\mathrm{D}$ \\
\hline PIK3R2 & phosphoinositide-3-kinase, regulatory subunit 2 & & $\mathrm{~S}$ & $\mathrm{U}$ \\
\hline PMAIP1 & phorbol-12-myristate-13-acetate-induced protein 1 & & $\mathrm{~S}$ & $\mathrm{U}$ \\
\hline$R A F 1$ & v-raf-1 murine leukemia viral oncogene homolog 1 & S & & \\
\hline RELA & $\begin{array}{l}\text { v-rel avian reticuloendotheliosis viral oncogene } \\
\text { homolog A }\end{array}$ & & $\mathrm{S}$ & \\
\hline TNFRSF10B & tumor necrosis factor receptor superfamily, member $10 \mathrm{~b}$ & & & $\mathrm{U}$ \\
\hline TNFRSF1A & tumor necrosis factor receptor superfamily, member $1 \mathrm{~A}$ & & $\mathrm{~S}$ & U \\
\hline TRAF2 & TNF receptor-associated factor 2 & & $\mathrm{~S}$ & \\
\hline TUBA1C & tubulin, $\alpha 1 \mathrm{~b}$ & I & & \\
\hline TUBA3D & tubulin, $\alpha 3 c$ & I & & \\
\hline TUBA4A & tubulin, $\alpha 4 a$ & & & $\mathrm{U}$ \\
\hline XIAP & X-linked inhibitor of apoptosis & & $S$ & \\
\hline
\end{tabular}

In PTC (21 significantly up-regulated andseven down-regulated apoptosis genes), we found SPINT2 to be significantly synergistically expressed with 34 apoptosis genes, but with no significant antagonistically or independently expressed partners. This is a substantial increase from the six synergistically, one antagonistically and four independently expressed apoptosis partners of SPINT2 in NOR. Interestingly, none of the significant correlations in NOR (with: ACTG1, ATF4, CASP9, CTSL, CYCS, NFKB1) were maintained in PTC.

What effect the overexpression of an otherwise stably expressed but not regulated gene in PTC (SPINT2) may have on cancer cells? Most probably, owing to the substantial expression synergistic coordination with apoptosis genes, the experimental overexpression of SPINT2 would up-regulate many of these genes, forcing the commanded (PTC) cells to enter programmed death.

There was no way to validate this hypothesis on the patient from whom we had profiled the thyroid tumor. However, we tested the general hypothesis that expression coordination with one gene predicts expression regulation when the expression of that gene is experimentally manipulated. For this purpose, we analyzed the transcriptomes of the TC cell lines BCPAP and 8505C cells before and after stable lentiviral transfection with either DDX19B, NEMP1, PANK2 or UBALD1 [8]. Figure 7a,b plots the correlation coefficient with $D D X 19 B$ in the untreated cells against the fold-changes (negative for down-regulation) of the genes in the transfected cells. They clearly show that expression coordination predicts ( $>86 \%)$ the expression regulation with reasonable accuracy. Similar validation (83-91\%) was obtained for the same cell lines transfected with either NEMP1, PANK2 or UBALD1. Based on this validation, Figure $7 \mathrm{c}$ illustrates the predicted regulations of apoptosis genes if the expression level of SPINT2 in PTC is significantly increased.

In Figure 7c, we used the uniform contribution of the significantly altered genes to the percentages of (up-/down-) regulated genes. Note that from 21 up-regulated and six down-regulated genes in untreated PTC, overexpression of SPINT2 may result in 48 up-regulated and six down-regulated genes. The expression of six genes, BBC3, DAB2IP, DIABLO, PIK3R2, PMAIP1, TNFRSF1A, which are already up-regulated in PTC may be further increased by treatment, while the down-regulation of GZMB in untreated PTC may be recovered by overexpressing SINT2. 


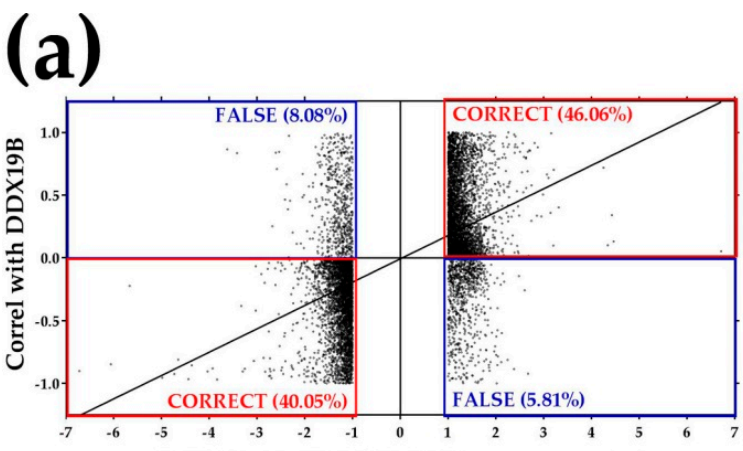

(BCPAP +DDX19B)/(BCPAP + empty vector) (b)

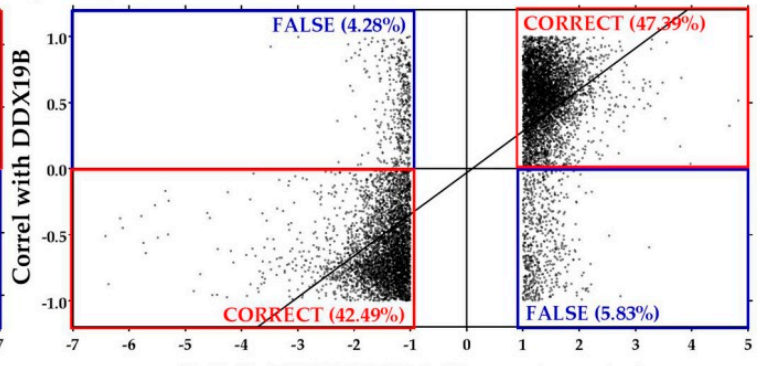

$(8505 \mathrm{C}+\mathrm{DDX} 19 \mathrm{~B}) /(8505 \mathrm{C}+$ empty vector $)$

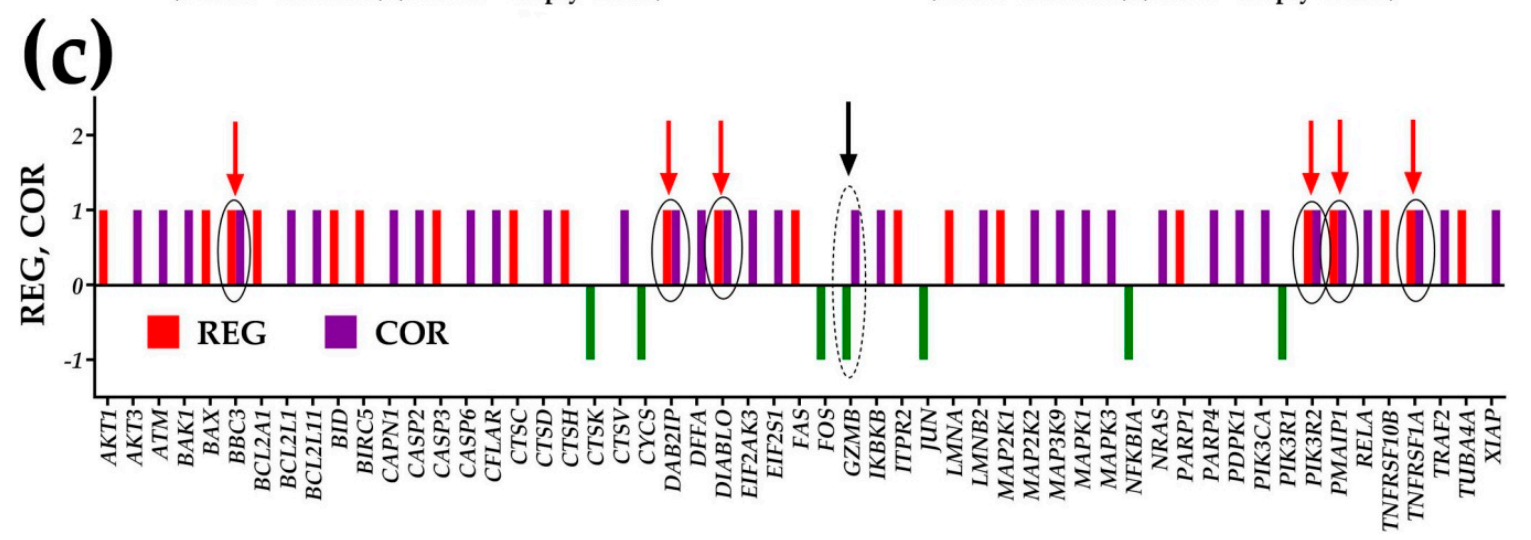

Figure 7. Prediction of the ripple effects of experimental gene regulation. (a) Expression coordination with $D D X 19 B$ in untreated BCAP cells accurately predicts $86.11 \%(40.05+46.06)$ the type of the expression regulation in BCAP cells stably transfected with DDX19B; (b) Expression coordination with DDX19B in untreated 8505 C cells accurately predicts $89.88 \%(42.49+47.39)$ of the type of the expression regulation in $8505 C$ cells stably transfected with DDX19B; (c) Predicted regulation (1 for up-regulation and -1 for down-regulation) of apoptotic genes in PTC following experimental overexpression of SPINT2. REG = significant $(1=$ up-regulation,$-1=$ down-regulation $)$. COR $=$ significant expression synergism. Only the regulated genes in the untreated PTC and those expected to be regulated in treated PTC are represented. Red arrows indicate combined effect in treated tumor of regulation and expression synergism in untreated PTC. The black arrow indicates the down-regulation in untreated PTC expected to be compensated by the overexpression of SPINT2.

\section{Discussion}

Although with no molecular biology validation, the bioinformatics analysis of the gene expression profiles in the cancer nodule and surrounding normal tissue of a surgically removed papillary tumor produced some very interesting results, out of which the most important are:

1. Each cell phenotype from the tumor is governed by a different gene hierarchy and a distinct organization of its transcriptome;

2. As selected from the most altered genes in a large population of cancer patients, the biomarkers have low GCH and therefore little therapeutic value;

3. The GMR of the cancer nodule is the most legitimate target of the gene therapy because it is the most influential gene for cancer cells while having very little role in the surrounding normal cells;

4. SPINT2 was identified as the GMR of the PTC nodule of the profiled tumor and a gene with very low GCH score in NOR;

5. The up-regulation of the synergistically expressed apoptosis genes in untreated PTC following the experimental SPINT2 overexpression was identified as a potential mechanism of selectively killing the cancer cells. 
The analysis presented in this report is consistent with the genomic fabric paradigm [11] that considers the transcriptome as a multi-dimensional object subjected to a dynamic set of expression correlations among the genes. The traditional transcriptomic analysis is limited to the expression level of individual genes and comparisons of the expression levels of distinct genes in the same condition or of the same gene in different conditions. Our procedure considerably enlarges the transcriptomic information by considering for each gene not one, but three independent features and all possible combinations of these features to compare the genes and groups of genes in the same condition or across various conditions.

Although high levels of EEF1A1 were reported in renal cell carcinoma [27], we found this gene to have the highest expression in NOR and one of the highest levels in PTC (68.47), albeit not significantly down-regulated. A high expression of NPC2 and its significant elevation in PTC were also detected in meta-analyses of public PTC transcriptomes [28]. Overexpression of CHI3L1, the most up-regulated gene in the analyzed PTC, was reported as associated with metastatic PTC [29] and its recurrence [30]. Significantly decreased expression of TFF3, the most down-regulated gene in our study, was also reported in several other studies (e.g., [31]).

In addition to illustrating the independence of the three features, Figure 1 provides also some interesting findings and confirmations of results reported by other authors. For instance, the high expression of CTSH in PTC (up-regulated by $6.78 \mathrm{x}$ with respect to NOR) was related to the tumor progression and migration of cancer cells [32].

The median REV has a statistically significant $\left(p\right.$-value $\left.=7.79 \times 10^{-5}\right)$ decrease from 39.75 in NOR to 38.69 in PTC. According to the Second Law of Thermodynamics, the significantly larger overall expression variability in NOR than in PTC indicates not only relaxed control by the homeostatic mechanisms (average $\mathrm{REC}_{\mathrm{NOR}}=0.084$, average $\mathrm{REC}_{\mathrm{PTC}}=0.113$ ), but also that NOR is closer to the thermodynamic (here physiological) equilibrium. Supporting this assertion is the reduction in the median REV observed by us in all other gene expression studies on animal models of human diseases (e.g., [33-35]) and in tissues of animals subjected to various stresses (e.g., [36-38] or to genetic manipulations (e.g., [39,40]). The high expression variability of CFLAR (a key anti-apoptosis regulator [41]) in NOR (REV = 102.93) may explain the adaptability of the apoptosis pathway to a large spectrum of environmental conditions. The CFLAR REV dramatic reduction in PTC $($ REV = 29.41) shows the need for tighter control of resisting apoptosis in cancer. Moreover, its reduction in expression level (in PTC by -1.64x) was associated with delayed apoptosis [41].

The observed down-regulation of FOS in PTC (Figure 2) confirms the findings of some groups [42,43] but contradicts its frequent (however not 100\%) up-regulation reported by another group in 40 patients with thyroid cancer and 20 with benign thyroid diseases [44]. Let us analyze what measure of regulation is the most informative and use the examples of FOS and KIT (another gene down-regulated in thyroid cancer [45]). Although both genes account as units for the percentage of the down-regulated genes, they contribute $-2.06 \mathrm{x}$ and $-8.15 \mathrm{x}$ as expression ratios and -46.28 and -3.76 as WIRs. Since WIR is a more comprehensive measure, FOS regulation appears to be the most important factor in the alteration of this group of genes. Indeed, FOS protein is an important player in cell proliferation, differentiation, transformation and apoptotic cell death.

Among the significantly regulated genes from the KEGG-derived THS pathway (Figure 3), only PAX8 $(-1.94 \mathrm{x})$ was previously related to the thyroid cancer, albeit to the follicular form. Moreover, we found that peroxisome proliferator-activated receptor $\gamma(P P A R G)$ whose fusion with PAX8 is considered an important trigger of the FTC [46], was likewise significantly down-regulated $(-4.99 x)$. Interestingly, in Figure 3, the two glutathione peroxidases, GPX1 (1.60x) and GPX3 (-1.84x), were oppositely regulated. Since the down-regulation of GPX1 was reported to augment the pro-inflammatory cytokine-induced redox signaling and endothelial cell activation [47], one may assume that up-regulation of GPX1 will do the opposite, i.e., diminish the pro-inflammatory cytokine-induced redox signaling. As such, the PTC cells will become more resistant to the inflammatory response. 
According to the KEGG map hsa04110, some of the regulated cell-cycle genes (Figure 4) were associated with a wide diversity of cancers. Thus, up-regulation of CDKN1A was associated with cervical cancer [48] and down-regulation of $C D K N 1 C$ with gastric cancer [49]. As stated in [3], up-regulation/mutation of $C D K N 2 A$ was detected in numerous cancer forms: neoplasms (squamous cell, ductal, lobular, cystic, mucinous, serous, mesothelial, lipomathous, myomathous, thymic epithelial, complex, mixed), adenomas, adenocarcionmas, gliomas, nevi and melanomas, transitional cell papillomas and carcinomas, mature B-cell lymphomas, soft tissue tumors and sarcomas. CDKN2B was associated with malignant pleural mesothelioma, osteosarcoma and meningioma. However, we found no report associating these genes with thyroid cancer. Unfortunately, one of the most cancer-related genes, TP53 [50], was not quantified in this experiment due to the corrupted probing spot in one of the microarrays, which can be seen as a major limitation of the study.

As illustrated in Figure 5 for interlinks between the five complexes of the oxidative phosphorylation, cancer remodels the gene networks, profoundly perturbing the mitochondrial function [51]. Among others, 10 synergistically expressed gene pairs in NOR are switched into antagonistically expressed pairs in PTC: NDUFA10-SDHD, CYC1-COX1, COX10-ATP6V0B, COX10-ATP6V0C, COX5B-LHPP, COX6A1-ATV1B2, COX6A1-LHPP, COX6A2-ATP6V0B, COX6A2-ATP6V1A, COX7C-ATP6V1G2. These switches, the cancellation of all significant antagonisms and the added synergisms increase the expression synchrony of the pathway genes [17] and remove the controlling bottlenecks. In a synergistic pair, the up-regulation of one gene triggers the up-regulation of the other. Although in this experiment we did not detect significantly altered expressions of NDUFA10 and SDHD, their significant synergism in PTC may explain why they are both up-regulated in oral cancer [52].

Given the never-repeatable set of risk factors, each patient is unique and therefore their gene hierarchy is unique. Although the chance of finding the same GMR in two persons is about $1 / 20,000$ and that of the first two genes is $1 / 400$ million, from the first three genes up, the number of possibilities $\left(7.9988 \times 10^{12}\right)$ exceeds by far the Earth human population. Therefore, the top three genes are enough to uniquely represent the cancer of each person at a given time. In our studied PTC, the top three genes were: SPINT2, RPAP3 and BZW,1 with none of them significantly regulated with respect to NOR.

SPINT2, the identified GMR of the profiled PTC (Figure 6), was previously reported by several groups to be involved in the development and progression of a wide diversity of forms of cancer [53]. Among others, SPINT2 was associated with metastatic osteosarcoma [54], ovarian cancer [55], glioma/glioblastoma [56,57], prostate cancer [58] and non-small lung cancer [59], leukemia [60] and cervical carcinoma [61]. RPAP3, essential for assembling chaperone complexes [62], was linked to hypoxia-adapted cancer cells [63] and BZW,1 was associated with ovarian [64], lung [65] and salivary gland [66] cancers. However, we found no mention in the literature about the role of these first three genes in any form of thyroid cancer.

In Figure 7 and Table 1, we tested whether expression synergism with apoptosis genes may be one of the mechanisms by which manipulation of SPINT2 expression is lethal to the PTC cells but not to the NOR cells. First, we determined the significant coordination of SPINT2 with apoptosis genes in both NOR and PTC and found a substantial increase in the expression synergism in PTC. Then, we tested the predictive value of the expression coordination by profiling two standard human TC cell lines before and after stable transfection with four genes selected, only to have substantially different GCHs in the two cell lines. Although DDX19B and PANK2 (but not NEMP1 and UBALD1) were synergistically expressed with SPINT2 in PTC, there are no reports relating these genes with SPINT2 in any form of cancer. As mentioned in [8], NEMP1 and PANK2 had higher GCHs and induced larger transcriptomic alterations in the BCPAP than in the $8505 \mathrm{C}$ cells. In contrast, DDX19B and UBALD1 had higher GCHs and induced larger transcriptomic alterations in the 8505C than in the BCPAP cells. Figure 7a,b confirms our previous findings that expression correlation with one gene predicts what genes are regulated when the expression of that gene is manipulated. A similar conclusion was drawn in [67], where we had shown that most genes are synergistically/antagonistically expressed with Gja (encoding the gap junction protein $\mathrm{Cx} 43$ ) in the brain and hearts of wildtype mice are down-/up-regulated in 
the brain and hearts of $\mathrm{Cx} 43 \mathrm{KO}$ mice. Therefore, as illustrated in Figure 7c, we expect that, due to the synergism, the overexpression of SPINT2 will force the PTC cells into programmed death by up-regulating numerous apoptosis genes.

\section{Conclusions}

Owing to the matchless set of conditioning factors, each human is unique and, despite all similarities, the transcriptomes of one person's cell phenotypes can never be identical with those of another person. In a profiled metastatic clear cell renal cell carcinoma [34], we found that even the transcriptomes of two cancer nodules isolated from the same kidney and categorized with the same Fuhrman grade 3 were largely different from each other. Moreover, some of the gene expression conditioning factors (environment, exposure to stress and toxins, medical treatment, diet, ageing etc.) are not constant, forcing the transcriptomes of cancer cells to continuously adapt. By consequence, the gene hierarchy is not only unique for each person and in each of his/her cancer nodules, but it changes over time. As such, this study provides strong reasons in favor of a really personalized and time-sensitive cancer gene therapy based on the manipulation of the gene master regulators.

Supplementary Materials: The following are available online at http://www.mdpi.com/2073-4425/11/9/1030/s1, Figure S1: GCH scores of the genes included in FoundationOne ${ }^{\circledR} \mathrm{CDx}$ assay. The assay explores genes with full coding exonic regions for the detection of substitutions, insertion-deletions (indels), and copy-number alterations (CNAs), genes with select intronic regions for the detection of gene rearrangements, one gene with a promoter region and one non-coding RNA gene. Several genes (BRAF, BRCA1, EGFR, FGFR1/3, KMT2A, MSH2, MYC. NOTCH2, RAF1, RARA) have both exonic and intronic regions used for detection.

Funding: This research was supported by the Texas A\&M University System Chancellor's Research Initiative (CRI) funding for the Center for Computational Systems Biology at the Prairie View A\&M University.

Conflicts of Interest: The author declares no conflict of interest.

\section{References}

1. Cancer Org Portal. Available online: https://www.cancer.org/cancer/thyroid-cancer (accessed on 26 July 2020).

2. Thyroid Cancer Portal. Available online: https://www.thyroid.org/thyroid-cancer/ (accessed on 26 July 2020).

3. Cancer Gov. Available online: https://portal.gdc.cancer.gov (accessed on 26 July 2020).

4. 1000 Genomes Project Consortium; Auton, A.; Brooks, L.D.; Durbin, R.M.; Garrison, E.P.; Kang, H.M.; Korbel, J.O.; Marchini, J.L.; McCarthy, S.; McVean, G.A.; et al. A global reference for human genetic variation. Nature 2015, 526, 68-74. [CrossRef] [PubMed]

5. Alexander, E.K.; Kennedy, G.C.; Baloch, Z.W.; Cibas, E.S.; Chudova, D.; Diggans, J.; Friedman, L.; Kloos, R.T.; LiVolsi, V.A.; Mandel, S.J.; et al. Preoperative diagnosis of benign thyroid nodules with indeterminate cytology. N. Engl. J. Med. 2012, 367, 705-715. [CrossRef] [PubMed]

6. Abdullah, M.I.; Junit, S.M.; Ng, K.L.; Jayapalan, J.J.; Karikalan, B.; Hashim, O.H. Papillary Thyroid Cancer: Genetic Alterations and Molecular Biomrker Investigations. Int. J. Med. Sci. 2019, 16, 450-460. [CrossRef]

7. Foundation Medicine. Available online: https://www.foundationmedicine.com/genomic-testing (accessed on 12 July 2020).

8. Iacobas, D.A.; Tuli, N.; Iacobas, S.; Rasamny, J.K.; Moscatello, A.; Geliebter, J.; Tiwari, R.K. Gene master regulators of papillary and anaplastic thyroid cancer phenotypes. Oncotarget 2018, 9, 2410-2424. [CrossRef] [PubMed]

9. Iacobas, S.; Ede, N.; Iacobas, D.A. The Gene Master Regulators (GMR) Approach Provides Legitimate Targets for Personalized, Time-Sensitive Cancer Gene Therapy. Genes 2019, 10, 560. [CrossRef] [PubMed]

10. Iacobas, D.A. Commentary on "The Gene Master Regulators (GMR) Approach Provides Legitimate Targets for Personalized, Time-Sensitive Cancer Gene Therapy. J. Cancer Immunol. 2019, 1, 31-33. [CrossRef]

11. Iacobas, D.A. The Genomic Fabric Perspective on the Transcriptome between Universal Quantifiers and Personalized Genomic Medicine. Biol. Theory 2016, 11, 123-137. [CrossRef]

12. National Center for Biotechnology Information. Available online: https://www.ncbi.nlm.nih.gov/gds/?term= iacobas (accessed on 26 July 2020). 
13. Zhang, H.; Xing, Z.; Mani, S.K.; Bancel, B.; Durantel, D.; Zoulim, F.; Tran, E.J.; Merle, P.; Andrisani, O. RNA helicase DEAD box protein 5 regulates Polycomb repressive complex 2/Hox transcript antisense intergenic RNA function in hepatitis B virus infection and hepatocarcinogenesis. Hepatology 2016, 64, 1033-1048. [CrossRef]

14. Liu, Y.; Tong, C.; Cao, J.; Xiong, M. NEMP1 Promotes Tamoxifen Resistance in Breast Cancer Cells. Biochem. Genet. 2019, 57, 813-826. [CrossRef]

15. Liu, Y.; Cheng, Z.; Li, Q.; Pang, Y.; Cui, L.; Qian, T.; Quan, L.; Dai, Y.; Jiao, Y.; Zhang, Z.; et al. Prognostic significance of the PANK family expression in acute myeloid leukemia. Ann. Transl. Med. 2019, 7, 261. [CrossRef]

16. Iacobas, D.A.; Iacobas, S.; Stout, R.; Spray, D.C. Cellular environment remodels the genomic fabrics of functional pathways in astrocytes. Genes 2020, 11, 520. [CrossRef]

17. Iacobas, D.A.; Iacobas, S.; Lee, P.R.; Cohen, J.E.; Fields, R.D. Coordinated Activity of Transcriptional Networks Responding to the Pattern of Action Potential Firing in Neurons. Genes 2019, 10, 754. [CrossRef] [PubMed]

18. Iacobas, D.A.; Iacobas, S.; Spray, D.C. Connexin 43 and the brain transcriptome of the newborn mice. Genomics 2007, 89, 113-123. [CrossRef]

19. Mathew, R.; Huang, J.; Iacobas, S.; Iacobas, D.A. Pulmonary Hypertension Remodels the Genomic Fabrics of Major Functional Pathways. Genes 2020, 11, 126. [CrossRef] [PubMed]

20. Iacobas, D.A.; Iacobas, S.; Tanowitz, H.B.; de Carvalho, A.C.; Spray, D.C. Functional genomic fabrics are remodeled in a mouse model of Chagasic cardiomyopathy and restored following cell therapy. Microbes Infect. 2018, 20, 185-195. [CrossRef] [PubMed]

21. Kanehisa, M.; Furumichi, M.; Tanabe, M.; Sato, Y.; Morishima, K. KEGG: New perspectives on genomes, pathways, diseases and drugs. Nucleic Acids Res. 2017, 45, D353-D361. [CrossRef]

22. Kyoto Encyclopedia of Genes and Genomes. Available online: http://www.genome.jp/kegg/ (accessed on 21 June 2020).

23. Liu, Y.C.; Yeh, C.T.; Lin, K.H. Molecular Functions of Thyroid Hormone Signaling in Regulation of Cancer Progression and Anti-Apoptosis. Int. J. Mol. Sci. 2019, 20, 4986. [CrossRef]

24. Bai, J.W.; Wei, M.; Li, J.W.; Zhang, G.J. Notch Signaling Pathway and Endocrine Resistance in Breast Cancer. Front. Pharmacol. 2020, 11, 924. [CrossRef]

25. Yuan, Y.; Ju, Y.S.; Kim, Y.; Li, J.; Wang, Y.; Yoon, C.J.; Yang, Y.; Martincorena, I.; Creighton, C.J.; Weinstein, J.N.; et al. Comprehensive molecular characterization of mitochondrial genomes in human cancers. Nat. Genet. 2020, 52, 342-352. [CrossRef]

26. Kobawala, T.P.; Trivedi, T.I.; Gajjar, K.K.; Patel, D.H.; Patel, G.H.; Ghosh, N.R. Significance of Interleukin-6 in Papillary Thyroid Carcinoma. J. Thyroid. Res. 2016, 6178921. [CrossRef]

27. Bao, Y.; Zhao, T.L.; Zhang, Z.Q.; Liang, X.L.; Wang, Z.X.; Xiong, Y.; Lu, X.; Wang, L.H. High eukaryotic translation elongation factor 1 alpha 1 expression promotes proliferation and predicts poor prognosis in clear cell renal cell carcinoma. Neoplasma 2020, 67, 78-84. [CrossRef] [PubMed]

28. Wu, C.C.; Lin, J.D.; Chen, J.T.; Chang, C.M.; Weng, H.F.; Hsueh, C.; Chien, H.P.; Yu, J.S. Integrated analysis of fine-needle-aspiration cystic fluid proteome, cancer cell secretome, and public transcriptome datasets for papillary thyroid cancer biomarker discovery. Oncotarget 2018, 9, 12079-12100. [CrossRef] [PubMed]

29. Luo, D.; Chen, H.; Lu, P.; Li, X.; Long, M.; Peng, X.; Huang, M.; Huang, K.; Lin, S.; Tan, L.; et al. CHI3L1 overexpression is associated with metastasis and is an indicator of poor prognosis in papillary thyroid carcinoma. Cancer Biomark. 2017, 18, 273-284. [CrossRef] [PubMed]

30. Cheng, S.P.; Lee, J.J.; Chang, Y.C.; Lin, C.H.; Li, Y.S.; Liu, C.L. Overexpression of chitinase-3-like protein 1 is associated with structural recurrence in patients with differentiated thyroid cancer. J. Pathol. 2020, e5503. [CrossRef]

31. Oczko-Wojciechowska, M.; Pfeifer, A.; Jarzab, M.; Swierniak, M.; Rusinek, D.; Tyszkiewicz, T.; Kowalska, M.; Chmielik, E.; Zembala-Nozynska, E.; Czarniecka, A.; et al. Impact of the Tumor Microenvironment on the Gene Expression Profile in Papillary Thyroid Cancer. Pathobiology 2020, 87, 143-154. [CrossRef] [PubMed]

32. Jevnikar, Z.; Rojnik, M.; Jamnik, P.; Doljak, B.; Fonovic, U.P.; Kos, J. Cathepsin H mediates the processing of talin and regulates migration of prostate cancer cells. J. Biol. Chem. 2013, 288, 2201-2209. [CrossRef]

33. Iacobas, D.A.; Iacobas, S.; Werner, P.; Scemes, E.; Spray, D.C. Alteration of transcriptomic networks in adoptive-transfer experimental autoimmune encephalomyelitis. Front. Integr. Neurosci. 2007, 1. [CrossRef] 
34. Iacobas, D.A.; Iacobas, S. Towards a Personalized Cancer Gene Therapy: A Case of Clear Cell Renal Cell Carcinoma. Cancer Oncol. Res. 2017, 5, 45-52. [CrossRef]

35. Frigeri, A.; Iacobas, D.A.; Iacobas, S.; Nicchia, G.P.; Desaphy, J.-F.; Camerino, D.C.; Svelto, M.; Spray, D.C. Effect of microagravity on brain gene expression in mice. Exp. Brain Res. 2008, 191, 289-300. [CrossRef]

36. Iacobas, D.A.; Fan, C.; Iacobas, S.; Spray, D.C.; Haddad, G.G. Transcriptomic changes in developing kidney exposed to chronic hypoxia. Biochem. Biophys. Res. Commun. 2006, 349, 329-338. [CrossRef]

37. Iacobas, D.A.; Fan, C.; Iacobas, S.; Haddad, G.G. Integrated transcriptomic response to cardiac chronic hypoxia: Translation regulators and response to stress in cell survival. Funct. Integr. Genom. 2008, 8, 265-275. [CrossRef] [PubMed]

38. Iacobas, D.A.; Iacobas, S.; Haddad, G.G. Heart rhythm genomic fabric in hypoxia. Biochem. Biophys. Res. Commun. 2010, 391, 1769-1774. [CrossRef] [PubMed]

39. Iacobas, D.A.; Urban, M.; Iacobas, S.; Scemes, E.; Spray, D.C. Array analysis of gene expression in connexin 43 null astrocytes. Physiol. Genom. 2003, 15, 177-190. [CrossRef] [PubMed]

40. Iacobas, D.A.; Iacobas, S.; Urban-Maldonado, M.; Scemes, E.; Spray, D.C. Similar transcriptomic alterations in Cx43 knock-down and knock-out astrocytes. Cell Commun. Adhes. 2008, 15, 195-206. [CrossRef] [PubMed]

41. Surmiak, M.; Hubalewska-Mazgaj, M.; Wawrzycka-Adamczyk, K.; Musiał, J.; Sanak, M. Delayed neutrophil apoptosis in granulomatosis with polyangiitis: Dysregulation of neutrophil gene signature and circulating apoptosis-related proteins. Scand. J. Rheumatol. 2020, 49, 57-67. [CrossRef]

42. Zhao, Y.; Liu, X.; Zhong, L.; He, M.; Chen, S.; Wang, T.; Ma, S. The combined use of miRNAs and mRNAs as biomarkers for the diagnosis of papillary thyroid carcinoma. Int. J. Mol. Med. 2015, 36, 1097-1103. [CrossRef]

43. Deligiorgi, M.V.; Mahaira, H.; Eftychiadis, C.; Kafiri, G.; Georgiou, G.; Theodoropoulos, G.; Konstadoulakis, M.M.; Zografos, E.; Zografos, G.C. RANKL, OPG, TRAIL, KRas, and c-Fos expression in relation to central lymph node metastases in papillary thyroid carcinoma. J. BU ON Off. J. Balk. Union Oncol. 2018, 23, 1029-1040.

44. Kataki, A.; Sotirianakos, S.; Memos, N.; Karayiannis, M.; Messaris, E.; Leandros, E.; Manouras, A.; Androulakis, G. P53 and C-FOS overexpression in patients with thyroid cancer: An immunohistochemical study. Neoplasma 2003, 50, 26-30.

45. Franceschi, S.; Lessi, F.; Panebianco, F.; Tantillo, E.; La Ferla, M.; Menicagli, M.; Aretini, P.; Apollo, A.; Naccarato, A.G.; Marchetti, I.; et al. Loss of c-KIT expression in thyroid cancer cells. PLoS ONE 2017, 12, e0173913. [CrossRef]

46. Chu, Y.H.; Sadow, P.M. Noninvasive Follicular Thyroid Neoplasm with Papillary-Like Nuclear Features (NIFTP): Diagnostic Updates and Molecular Advances. In Seminars in Diagnostic Pathology; WB Saunders: Philadelphia, PA, USA, 2020.

47. Lubos, E.; Kelly, N.J.; Oldebeken, S.R.; Leopold, J.A.; Zhang, Y.Y.; Loscalzo, J.; Handy, D.E. Glutathione peroxidase-1 deficiency augments proinflammatory cytokine-induced redox signaling and human endothelial cell activation. J. Biol. Chem. 2011, 286, 35407-35417. [CrossRef]

48. Cardoso, M.F.S.; Castelletti, C.H.M.; Lima-Filho, J.L.; Martins, D.B.G.; Teixeira, J.A.C. Putative biomarkers for cervical cancer: SNVs, methylation and expression profiles. Mutat. Res. 2017, 773, 161-173. [CrossRef] [PubMed]

49. Mei, L.; Shen, C.; Miao, R.; Wang, J.Z.; Cao, M.D.; Zhang, Y.S.; Shi, L.H.; Zhao, G.H.; Wang, M.H.; Wu, L.S.; et al. RNA methyltransferase NSUN2 promotes gastric cancer cell proliferation by repressing p57Kip2 by an m5C-dependent manner. Cell Death Dis. 2020, 11, 270. [CrossRef] [PubMed]

50. Matsuda, S.; Murakami, M.; Ikeda, Y.; Nakagawa, Y.; Tsuji, A.; Kitagishi, Y. Role of tumor suppressor molecules in genomic perturbations and damaged DNA repair involved in the pathogenesis of cancer and neurodegeneration (Review). Biomed. Rep. 2020, 13, 10. [CrossRef]

51. Księżakowska-Łakoma, K.; Żyła, M.; Wilczyński, J.R. Mitochondrial dysfunction in cancer. Prz. Menopauzalny 2014, 13, 136-144. [CrossRef]

52. Huang, Y.P.; Chang, N.W. PPAR $\alpha$ modulates gene expression profiles of mitochondrial energy metabolism in oral tumorigenesis. Biomedicine 2016, 6, 3. [CrossRef]

53. Roversi, F.M.; Olalla Saad, S.T.; Machado-Neto, J.A. Serine peptidase inhibitor Kunitz type 2 (SPINT2) in cancer development and progression. Biomed. Pharmacother. 2018, 101, 278-286. [CrossRef]

54. Guan, X.; Guan, Z.; Song, C. Expression profile analysis identifies key genes as prognostic markers for metastasis of osteosarcoma. Cancer Cell Int. 2020, 20, 104. [CrossRef] 
55. Graumann, J.; Finkernagel, F.; Reinartz, S.; Stief, T.; Brödje, D.; Renz, H.; Jansen, J.M.; Wagner, U.; Worzfeld, T.; Pogge von Strandmann, E.; et al. Multi-platform affinity proteomics identify proteins linked to metastasis and immune suppression in ovarian cancer plasma. Front. Oncol. 2019, 9, 1150. [CrossRef] [PubMed]

56. Liu, F.; Cox, C.D.; Chowdhury, R.; Dovek, L.; Nguyen, H.; Li, T.; Li, S.; Ozer, B.; Chou, A.; Nguyen, N.; et al. SPINT2 is hypermethylated in both IDH1 mutated and wild-type glioblastomas, and exerts tumor suppression via reduction of c-Met activation. J. Neurooncol. 2019, 142, 423-434. [CrossRef] [PubMed]

57. Pereira, M.S.; Celeiro, S.P.; Costa, Â.M.; Pinto, F.; Popov, S.; de Almeida, G.C.; Amorim, J.; Pires, M.M.; Pinheiro, C.; Lopes, J.M.; et al. Loss of SPINT2 expression frequently occurs in glioma, leading to increased growth and invasion via MMP2. Cell. Oncol. 2020, 43, 107-121. [CrossRef] [PubMed]

58. Wu, L.; Shu, X.; Bao, J.; Guo, X.; Kote-Jarai, Z.; Haiman, C.A.; Eeles, R.A.; Zheng, W.; PRACTICAL, CRUK, BPC3, CAPS, PEGASUS Consortia. Analysis of Over 140,000 European Descendants Identifies Genetically Predicted Blood Protein Biomarkers Associated with Prostate Cancer Risk. Cancer Res. 2019, 79, 4592-4598. [CrossRef] [PubMed]

59. Ma, Z.; Liu, D.; Li, W.; Di, S.; Zhang, Z.; Zhang, J.; Xu, L.; Guo, K.; Zhu, Y.; Han, J.; et al. STYK1 promotes tumor growth and metastasis by reducing SPINT2/HAI-2 expression in non-small cell lung cancer. Cell Death Dis. 2019, 10, 435. [CrossRef] [PubMed]

60. Roversi, F.M.; Cury, N.M.; Lopes, M.R.; Ferro, K.P.; Machado-Neto, J.A.; Alvarez, M.C.; Dos Santos, G.P.; Giardini Rosa, R.; Longhini, A.L.; Duarte, A.D.S.S.; et al. Up-regulation of SPINT2/HAI-2 by Azacytidine in bone marrow mesenchymal stromal cells affects leukemic stem cell survival and adhesion. J. Cell. Mol. Med. 2019, 23, 1562-1571. [CrossRef] [PubMed]

61. Wang, N.; Che, Y.; Yin, F.; Yu, F.; Bi, X.; Wang, Y. Study on the methylation status of SPINT2 gene and its expression in cervical carcinoma. Cancer Biomark. 2018, 22, 435-442. [CrossRef] [PubMed]

62. Rodríguez, C.F.; Llorca, O. RPAP3 C-Terminal Domain: A Conserved Domain for the Assembly of R2TP Co-Chaperone Complexes. Cells 2020, 9, 1139. [CrossRef] [PubMed]

63. Kawachi, T.; Tanaka, S.; Fukuda, A.; Sumii, Y.; Setiawan, A.; Kotoku, N.; Kobayashi, M.; Arai, M. Target identification of the marine natural products Dictyoceratin-A and $-\mathrm{C}$ as selective growth inhibitors in cancer cells adapted to hypoxic environments. Mar. Drugs 2019, 17, 163. [CrossRef]

64. Liu, F.; Zhao, H.; Gong, L.; Yao, L.; Li, Y.; Zhang, W. MicroRNA-129-3p functions as a tumor suppressor in serous ovarian cancer by targeting BZW1. Int. J. Clin. Exp. Pathol. 2018, 11, 5901-5908.

65. Chiou, J.; Chang, Y.C.; Jan, Y.H.; Tsai, H.F.; Yang, C.J.; Huang, M.S.; Yu, Y.L.; Hsiao, M. Overexpression of BZW1 is an independent poor prognosis marker and its down-regulation suppresses lung adenocarcinoma metastasis. Sci. Rep. 2019, 9, 14624. [CrossRef]

66. Li, S.; Chai, Z.; Li, Y.; Liu, D.; Bai, Z.; Li, Y.; Li, Y.; Situ, Z. BZW1, a novel proliferation regulator that promotes growth of salivary muocepodermoid carcinoma. Cancer Lett. 2009, 284, 86-94. [CrossRef]

67. Iacobas, D.A.; Iacobas, S.; Spray, D.C. Connexin-dependent transcellular transcriptomic networks in mouse brain. Prog. Biophys. Mol. Biol. 2007, 94, 168-184. [CrossRef]

(C) 2020 by the author. Licensee MDPI, Basel, Switzerland. This article is an open access article distributed under the terms and conditions of the Creative Commons Attribution (CC BY) license (http://creativecommons.org/licenses/by/4.0/). 